Dear Author,

Please, note that changes made to the HTML content will be added to the article before publication, but are not reflected in this PDF.

Note also that this file should not be used for submitting corrections. 


\title{
Q2 Previous exposure to intact speech increases intelligibility of its digitally degraded counterpart as a function of stimulus complexity
}

\author{
Q3 Maria Hakonen ${ }^{\mathrm{a}, \mathrm{b}, *}$, Patrick J.C. May ${ }^{\mathrm{c}}$, Jussi Alho ${ }^{\mathrm{a}}$, Paavo Alku ${ }^{\mathrm{d}}$, Emma Jokinen ${ }^{\mathrm{d}}$, \\ Iiro P. Jääskeläinen ${ }^{\mathrm{a}}$, Hannu Tiitinen ${ }^{\mathrm{a}, \mathrm{b}}$

\footnotetext{
a Brain and Mind Laboratory, Department of Neuroscience and Biomedical Engineering (NBE), School of Science, Aalto University, PO Box 12200 , FI-00076 AALTO, Finland

b BioMag Laboratory, PO Box 340, FI-00029 HUS, Helsinki University Central Hospital, Finland

c Special Laboratory Non-Invasive Brain Imaging, Leibniz Institute for Neurobiology, Brenneckestraße 6, D-39118 Magdeburg, Germany
} \\ d Department of Signal Processing and Acoustics, School of Electrical Engineering, Aalto University, PO Box 13000, FI-00076 AALTO, Finland
}

\section{A R T I C L E I N F O}

\section{Article history:}

Received 27 June 2015

Accepted 10 October 2015

Available online xxxx

\section{Keywords:}

Speech

Comprehension

Intelligibility

Acoustic distortion

Magnetoencephalography

Auditory neuroscience

\begin{abstract}
A B S T R A C T
Recent studies have shown that acoustically distorted sentences can be perceived as either unintelligible or intel- 22 ligible depending on whether one has previously been exposed to the undistorted, intelligible versions of the 23 sentences. This allows studying processes specifically related to speech intelligibility since any change between 24 the responses to the distorted stimuli before and after the presentation of their undistorted counterparts cannot 25 be attributed to acoustic variability but, rather, to the successful mapping of sensory information onto memory 26 representations. To estimate how the complexity of the message is reflected in speech comprehension, we ap- 27 plied this rapid change in perception to behavioral and magnetoencephalography (MEG) experiments using 28 vowels, words and sentences. In the experiments, stimuli were initially presented to the subject in a distorted 29 form, after which undistorted versions of the stimuli were presented. Finally, the original distorted stimuli 30 were presented once more. The resulting increase in intelligibility observed for the second presentation of the 31 distorted stimuli depended on the complexity of the stimulus: vowels remained unintelligible (behaviorally 32 measured intelligibility $27 \%$ ) whereas the intelligibility of the words increased from $19 \%$ to $45 \%$ and that of the 33 sentences from $31 \%$ to $65 \%$. This increase in the intelligibility of the degraded stimuli was reflected as an enhance- 34 ment of activity in the auditory cortex and surrounding areas at early latencies of $130-160 \mathrm{~ms}$. In the same re- 35 gions, increasing stimulus complexity attenuated mean currents at latencies of $130-160$ ms whereas at 36 latencies of 200-270 ms the mean currents increased. These modulations in cortical activity may reflect feedback 37 from top-down mechanisms enhancing the extraction of information from speech. The behavioral results suggest 38 that memory-driven expectancies can have a significant effect on speech comprehension, especially in acousti- 39 cally adverse conditions where the bottom-up information is decreased.
\end{abstract}

(c) 2015 Published by Elsevier Inc.

\section{Introduction}

Despite increasing efforts in the study of the neural basis of speech comprehension, the processes related to speech intelligibility, which is reflected as correctly identified speech content and arises out of the successful matching of bottom-up acoustic information to top-down memory representations, have remained largely unknown. One reason for this is that studies on speech intelligibility have typically either manipulated the acoustic structure of the speech signal or masked the speech stimulus using varying levels and types of noise. However, both the processing of acoustic features of the stimulus and cognitive operations related to the recognition of the content of speech sounds are reflected in

\footnotetext{
* Corresponding author at: Department of Neuroscience and Biomedical Engineering (NBE), School of Science, Aalto University, PO Box 12200, FI-00076 AALTO, Finland.

E-mail address: maria.hakonen@aalto.fi (M. Hakonen).
}

brain responses, and it is therefore difficult to distinguish their overlap- 57 ping contributions from one another.

Only a limited number of studies have examined the brain mecha- 59 nisms related to speech comprehension by manipulating stimulus 60 intelligibility without changing the acoustic structure of the stimulus. 61 Our recent magnetoencephalography (MEG) study (Tiitinen et al., 62 2012) introduced an experimental paradigm where the same set of 63 speech stimuli was presented to the subject in a distorted, undistorted, 64 and again in a distorted form. The intervening exposure to the undis- 65 torted versions of the sentences increased the intelligibility of the 66 distorted sentences considerably (i.e. the recognition rate increased 67 from $30 \%$ to $80 \%$ ), and this was reflected as stronger activation to the in- 68 telligible sentences in the auditory cortex and surrounding areas. A sim- 69 ilar approach to control acoustic variability was used by Giraud et al. 70 (2004) who measured functional magnetic resonance imaging (fMRI) 71 responses to a set of vocoded sentences before and after the subject 72 was trained to perceive these sentences correctly in a learning phase 73 
where normal speech and vocoded speech were paired. Since the left inferior frontal gyrus (Broca's area) responded more strongly to noisevocoded speech after training, the activation in this area was concluded to reflect speech intelligibility. Hannemann et al. (2007) described an electroencephalography (EEG) experiment where the subject first listened to unintelligible, digitally degraded words, after which half of the words were presented in undistorted, intelligible form and, finally, all degraded words were presented again. Those items which had been heard in the non-degraded form in the exposure sequence were more likely to be perceived as intelligible in the consecutive test sequence. Correct identification of the words was associated with an increase in induced gamma-band activity at left temporal electrode sites at around $350 \mathrm{~ms}$. Taken together, these studies suggest that topdown cognitive processes, observable in both behavioral and brain measures, enhance speech comprehension and clearly warrant further exploration.

Studies using fMRI have shown how the processing of intelligible speech takes place in multiple cortical areas: activity spreads from the primary auditory cortex at Heschl's gyrus to the areas of the temporal cortex anterior, posterior and inferior to the primary auditory cortex (Davis and Johnsrude, 2003; Friederici et al., 2010; Leff et al., 2008; Möttönen et al., 2006; Okada et al., 2010), as well as to prefrontal, premotor/motor and posterior inferotemporal regions (Leff et al., 2008; Davis and Johnsrude, 2003; Obleser et al., 2008, for a review, see Peelle et al., 2010). Recent studies have reported that the patterns of intelligibility-related brain activity under unfavorable listening conditions are not identical to those under favorable listening conditions (Davis and Johnsrude, 2007; Giraud et al., 2004; Hervais-Adelman et al., 2012; Shahin et al., 2009; Wild et al., 2012), promoting the hypothesis for the existence of a separate, possibly attention-related, neural mechanism subserving comprehension of degraded speech (Hervais-Adelman et al., 2012). However, the role of, for example, motor areas (Lotto et al., 2009; Scott et al., 2009) and the auditory cortex in speech intelligibility remain controversial (Giraud et al., 2004; Peelle et al., 2010).

In MEG and EEG measurements, auditory stimuli elicit a series of transient responses, the most prominent of which is the auditory N1 response, measured electrically, and its magnetic counterpart, the $\mathrm{N} 1 \mathrm{~m}$ (for reviews, see Näätänen and Picton, 1987; May and Tiitinen, 2010). In the case of long-duration stimuli ( $>300 \mathrm{~ms}$ ), the transient responses are followed by a sustained response that persists for the duration of the sound. The $\mathrm{N} 1 \mathrm{~m}$ response, generated in the auditory cortex and peaking approximately $100 \mathrm{~ms}$ after stimulus onset, is sensitive to the acoustic characteristics of speech sounds, such as the fundamental frequency (Mäkelä et al., 2002), intonation (Mäkelä et al., 2004), periodicity (Tiitinen et al., 2005; Yrttiaho et al., 2009) and phonological features (Obleser et al., 2004). The N1m has also been associated with the process of segregating speech signals from noise contributions (Miettinen et al., 2010, 2011, 2012). Most studies addressing sustained brain activity have used simplified stimuli, such as click trains (Galambos et al., 1981; Gutschalk et al., 2002; Hari et al., 1989), noise signals (Keceli et al., 2012), tones (Huotilainen et al., 1995; Okamoto et al., 2011), or vowels (Eulitz et al., 1995). However, the use of short-duration simplified stimuli may result in an incomplete picture of auditory analysis in the human brain. It is probable that the human brain is optimized for processing complex natural stimuli, such as connected speech (i.e. words and sentences). Therefore, studies geared strictly toward timelocked transient brain responses to brief stimuli lacking in information content should be complemented by investigations focusing on the sustained activity elicited by connected speech. This could potentially reveal how information is integrated over extended time spans, and how complex acoustic streams of sound are translated into meaningful utterances in the human brain.

The objective of the current MEG study was to examine the cortical mechanisms underlying speech comprehension under varying levels of speech intelligibility (i.e. using acoustically distorted and undistorted stimuli) and complexity (i.e. using vowel sounds, words, and 140 sentences). The experimental paradigm introduced in our previous 141 study (Tiitinen et al., 2012) was applied in the current study, with the 142 subject first presented with distorted stimuli, then with undistorted 143 versions of the same set of stimuli, and finally, with the distorted stimuli 144 again. Acoustically identical distorted stimuli were expected to be per- 145 ceived as either unintelligible or intelligible, depending on whether 146 the subject had previously been exposed to the undistorted (intact) ver- 147 sions of the stimuli. Our hypothesis was that both this behaviorally ob- 148 servable intelligibility effect and variations in stimulus complexity 149 should be accompanied by changes in both the dynamics and spread 150 of brain activity from the auditory cortex to adjacent cortical areas. By 151 exposing the subjects to the undistorted stimuli in the intermediate 152 phase of the experiment, the current experimental setup allows manip- 153 ulation of the intelligibility of the distorted stimuli without introducing 154 any acoustic changes to these stimuli. Thus, any difference in brain ac- 155 tivity elicited by the first and the second presentations of the distorted 156 stimuli cannot be attributed to changes in the acoustic structure but, 157 rather, to the processes directly involved with speech intelligibility. 158 The overall goal of this study was, therefore, to provide further insight 159 into how the top-down cognitive operations triggered by prior informa- 160 tion are able to turn even severely distorted acoustic signals into mean- 161 ingful cognitive entities by enhancing the extraction of relevant acoustic 162 features.

Behavioral and MEG measurements were carried out for two 166 separate groups of sixteen healthy volunteers, aged 19-33 years 167 (average age 22.4 years, SD 3.7 years; 8 male and 8 female; 15 right- 168 handed) in the behavioral measurements and 20-26 years (average 169 age 22.7 years, SD 1.6 years; 8 male and 8 female; 15 right-handed) in 170 the MEG measurements. The use of different sets of subjects was neces- 171 sary to avoid possible carry-over effects, whereby the presentation of 172 the intact stimuli in the first experiment would renders the distorted 173 stimuli intelligible in the second experiment, already at their first pre- 174 sentation. All volunteers had normal hearing and provided written in- 175 formed consent. The experiments were approved by the Ethical 176 Committee of Helsinki University Central Hospital.

\section{Stimulus material}

Vowels, words, and sentences were constructed using the Bitlips 179 TTS synthesizer (http://www.bitlips.fi/). The sentence set consisted of 180 192 Finnish sentences, comprising 3 to 7 words (sentence duration: 181 1.7-4.6 s; mean $3.1 \mathrm{~s}$; SD $0.6 \mathrm{~s}$ ). Each sentence started with the vowel 182 /a/, /e/, /i/ or /u/. The word set was created by separating the first 183 word of each sentence. Thus, the words $(0.31-1.40 \mathrm{~s}$ in duration, 184 mean 0.65 s; SD 0.18 ) in the word set were acoustically identical to 185 the initial words of the sentences. The vowel set included 200-ms in- 186 stances of all eight vowels of the Finnish language (/a/, /e/, /i/, /o/, /u/, 187 /y/, /ä/, /ö/). The stimuli were recorded at a sampling rate of $44.1 \mathrm{kHz} 188$ with an amplitude resolution of 16 bits.

In addition to the above undistorted (16-bit) stimuli, the experiment 190 utilized their distorted (1-bit) counterparts. The distorted versions of 191 the stimuli were produced by first resampling the undistorted stimuli 192 at $4.41 \mathrm{kHz}$ using Matlab resample routine. Second, the resampled 193 signals were compressed digitally through reduction of the amplitude 194 resolution (bit rate) of the signals with the 1-bit uniform scalar quanti- 195 fication (USQ) method (see Liikkanen et al., 2007; Gray, 1990). USQ ap- 196 proximates each sample of the speech signal waveform to the nearest 197 permitted level, the number of these depending on the number of bits 198 used in the quantization. For example, using 16-bit USQ, there are a 199 total of approx. 65000 quantization levels which allows precise 200 
modeling of the original speech waveform. In the case of 1-bit USQ the number of levels is reduced to two which results in speech being represented by a series of rectangular pulse forms. Because quantization is a non-linear process, the 1-bit USQ process is capable of producing new frequencies which is seen as degradation of the spectral fine structure of speech by new noisy harmonics. In addition to this, the USQ generates quantization noise which is manifested as flattening of the spectral envelope (Miettinen et al., 2010). In overall, the degraded speech stimuli of the study were flat in terms of the spectral envelope and consisted of the low frequencies of speech (frequencies higher than $2.2 \mathrm{kHz}$ were filtered out in resampling) and new noisy harmonics (generated by 1-bit USQ).

The stimuli were delivered as a mono signal to the subject's ears through Sennheiser HD headphones in the behavioral experiment and through a pair of plastic tubes and ear pieces (Etymotic Research Inc., IL, USA) in the MEG experiment. Sound intensity of the stimuli was set at $70 \mathrm{~dB}$ SPL. In the MEG experiment, the intensity was adjusted by measuring it with a sound level meter (Velleman DVM 805) at the tips of the tubes.

\section{Experimental design}

The study comprised two experiments. First, a behavioral experiment was designed to test the subject's ability to recognize the auditory stimuli. Second, the effects of acoustic distortion and intelligibility of the auditory stimuli on cortical activity was studied in an MEG experiment (Fig. 1).

The behavioral experiment, carried out in a soundproofed listening booth, consisted of three blocks: one comprising vowels, the second words, and the third sentences. The presentation order of the stimulus blocks was counterbalanced across subjects. During each stimulus block, the subject was first presented with distorted stimuli, then with the undistorted versions of the same set of stimuli, and finally with the distorted stimuli again. The vowel block contained 12 repetitions of eight vowels (/a/, /e/, /i/, /o/, /u/, /y/, /ä/, /ö/) presented in random order (i.e. 96 stimuli in total). At each vowel presentation, the eight alternative answers were presented on a computer screen to the subject whose task was to indicate with a mouse click which vowel had been presented or whether the vowel was unintelligible. Vowels which

vowels

words

$N=48$

$N=160$
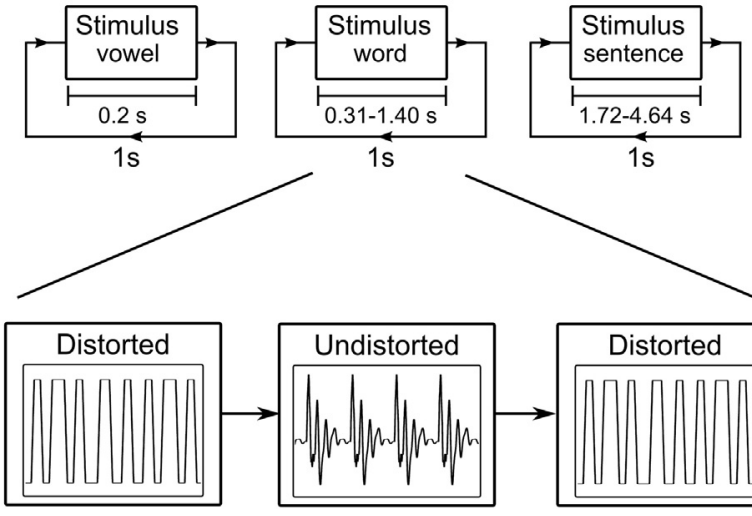

Fig. 1. Experimental design. The study was divided into behavioral and MEG experiments, each of which consisted of three blocks: one comprising vowels, the second words, and the third sentences. In each of the stimulus blocks, the subject was presented with acoustically distorted stimuli, followed by the undistorted versions of the same set of stimuli, after which the distorted stimuli were presented again. $N=$ number of stimuli. were correctly identified were classified as intelligible, those incorrectly 238 identified as unintelligible. The set of 192 words and sentences was di- 239 vided into four subsets ( 48 words/sentences per subset) and, similarly, 240 the 16 subjects were divided into four subgroups (four subjects per sub- 241 group). Each subgroup of the subjects was presented with one of the 242 word/sentence subsets. The total set of 48 words/sentences presented 243 for each subject was randomized. Following the presentation of each 244 word and sentence, the subject used a keypad to type what he/she 245 had heard. Correctly identified words were classified as identifiable 246 and misidentified words as unintelligible. Intelligibility scores for 247 sentences were computed by scoring the stems and suffixes of inflected 248 words separately after obvious spelling errors had been corrected. $\quad 249$

In the MEG experiment, the stimuli were presented in a passive (no 250 task) recording condition during which the subject was under instruc- 251 tion to watch a film without its soundtrack while ignoring the auditory 252 stimuli. Given the novelty of the experimental paradigm, the passive re- 253 cording condition in MEG was an essential starting point for the inves- 254 tigation since it provides brain events uncontaminated by the effects 255 of attentional engagement (arousal level, selective and/or sustained at- 256 tention, etc.) as well as of planning and the execution of motor re- 257 sponses. Similarly as the behavioral experiment, the MEG experiment 258 was divided into vowel, word and sentence blocks, in each of which 259 the same set of stimuli was presented in a distorted, undistorted, 260 and again in a distorted form. The presentation order of the stimulus 261 blocks was counterbalanced across subjects. In the vowel block, four 262 vowels (/a/, /e/, /i/, /u/) were repeated 120 times in random order. 263 These vowels were selected because they are maximally displaced 264 from each other in the two-dimensional space spanned by the first 265 and the second formant. To keep the duration of the MEG experiment 266 bearable to the subjects, a subset of 160 sentences was selected from 267 the total set of 192 sentences presented in the behavioral experiment. 268 The corresponding starting words of the sentences comprised the stim- 269 uli in the word block. The total set of 160 words/sentences was present- 270 ed in random order to each subject. The offset-to-onset interstimulus 271 interval (ISI) in all three blocks was $1 \mathrm{~s}$. The duration of the experiment 272 was $\sim 1.75 \mathrm{~h}$.

\section{MEG data acquisition}

Brain responses were recorded with a 306-channel whole head MEG 275 device (Vectorview 4-D, Neuromag Oy, Finland) in a magnetically 276 shielded room with a three-layer $\mu$-metal and aluminum cover (ETS- 277 Lindgren Euroshield Oy, Eura, Finland). The sampling rate was set at 278 $1.2 \mathrm{kHz}$. Horizontal and vertical eye movements were measured with 279 electro-oculography (EOG) using two electrode pairs placed above and 280 below the left eye and lateral to the eyes. Before recording, four head- 281 position indicator (HPI) coils were used to determine the position of 282 the subject's head relative to the MEG sensor array. A 3-D digitizer was 283 used to determine the locations of the HPI coils with respect to the 284 three anatomical landmarks (the nasion and the bilateral preauricular 285 points) that define a head-based coordinate system where the $x$-axis 286 passes through the preauricular points (positive to the right), the 287 $y$-axis passes through the nasion (positive to the front), and the $z$-axis 288 unit vector is the vector cross product of the $x$ and $y$ unit vectors. The 289 subject was instructed to remain stationary and to avoid blinking during 290 the measurement.

MEG data preprocessing

The raw MEG data was manually inspected to exclude gradiometer 293 sensors with a low signal-to-noise ratio (SNR). External noise was re- 294 moved from the raw data using the temporal extension of Signal- 295 Space Separation (tSSS; Taulu and Simola, 2006) as implemented with 296 the MaxFilter software (Elekta-Neuromag). For the transient analysis, 297 the raw data was band-pass filtered at 2-30 Hz with a 4th order 298 Butterworth infinite impulse response (IIR) filter with a length of 10 s. 299 
For the sustained field analysis, the raw data was low-pass filtered at $30 \mathrm{~Hz}$, since high-pass filtering abolishes sustained fields (May and Tiitinen, 2010; Mäkinen, 2006). After filtering, the epochs were computed and corrected with respect to a 100 -ms pre-stimulus baseline. For averaging the data, the data epochs were time-locked to stimulus onsets using information recorded on the trigger channel. A $500-\mathrm{ms}$ poststimulus time window was used for averaging transient responses. For the sustained field analysis, the responses elicited by words and sentences were averaged over a $600-\mathrm{ms}$ post-stimulus time window. To exclude the possible contributions caused by transient offset responses, a subset of 112 words exceeding $560 \mathrm{~ms}$ in duration was selected for the sustained field analysis. For the responses to sentences, the analysis was restricted to the sustained fields elicited by the corresponding subset of 112 sentences starting with the words exceeding $560 \mathrm{~ms}$. Epochs with magnetic field gradient amplitudes exceeding $2000 \mathrm{fT} / \mathrm{cm}$ were automatically discarded from both the transient and sustained filed analyses. EOG artifacts were removed from the epochs using fast independent component analysis (Gramfort et al., 2013; Hyvärinen and Oja, 2000). Fitting ICA after filtering and epoching allowed more reliable identification of the components that reflect EOG artifacts since the high-frequency noise and drifts as well as contaminated epochs were removed before EOG artifact identification. After removing the EOG artifacts, the epochs were averaged. The preprocessing was performed with the MNE software (Gramfort et al., 2013, 2014).

\section{Gradiometer analysis}

For the gradiometer analysis, nine gradiometer pairs centered over the left and right auditory cortices were divided into anterior, medial, and posterior subsets, and an average was calculated over the responses from the three gradiometer pairs within each subset. Response amplitude was determined as the magnitude of the gradiometer pair vector sum. The latencies and amplitudes of the $\mathrm{N} 1 \mathrm{~m}$ and $\mathrm{P} 2 \mathrm{~m}$ responses were estimated from the peak values of the anterior, medial and posterior vector sum magnitudes. The peak amplitudes of the $\mathrm{N} 1 \mathrm{~m}$ and $\mathrm{P} 2 \mathrm{~m}$ responses were identified as the local maximum within the respective time intervals of $110-170 \mathrm{~ms}$ and $180-300 \mathrm{~ms}$. Because the onsets and offsets of the vowels were smoothed with a 10-ms Hann window (ramp length $5 \mathrm{~ms}$ ) whereas for words and sentences a Hann window of $20 \mathrm{~ms}$ (ramp length $10 \mathrm{~ms}$ ) was used, the difference between the lengths of Hann window ramps ( $5 \mathrm{~ms}$ ) was added to the latencies of the transient responses elicited by vowels to make them comparable to the latencies of the transient responses elicited by words and sentences.

Sustained fields were analyzed by dividing the gradiometer pairs into ten location-based subsets: occipital, parietal, and left and right frontal, temporal, sensorimotor and occipitotemporal subsets. For each subset, the magnitudes of the gradiometer-pair vector sums were averaged, and this average was then used to quantify the magnitude of the sustained field as the mean of the response in the 400-560 ms time window.

\section{Current distribution estimates}

To estimate the spatial distribution of cortical activity, depthweighted minimum-norm estimates (MNEs; Hämäläinen and Ilmoniemi, 1994; Lin et al., 2006a,b) were generated with the MNE Software (Gramfort et al., 2014). Moreover, dynamic statistical map (dSPM) estimates (Dale et al., 2000) were generated to provide an indication of the cortical locations where the MNE estimates had the highest SNR. For the MNE and the dSPM estimates, noise-covariance matrices were computed from the 100-ms pre-stimulus baselines of the data. Forward solutions and inverse operators were calculated for each stimulus by employing a single-compartment boundary-element model (BEM) computed using average head and skull surface reconstructions provided by the FreeSurfer software. A loose orientation constraint 362 was used to control the source orientations (Lin et al., 2006a). The 363 MNE and the dSPM estimates were calculated separately for each indi- 364 vidual subject, for each type of stimulus (i.e. vowels, words, and 365 sentences), and for each condition (i.e. the first and the second presen- 366 tations of the distorted stimuli and the presentation of the undistorted 367 stimuli). The dSPM estimates were averaged over a 40-ms time window 368 centered at the peaks of the $\mathrm{N} 1 \mathrm{~m}$ and $\mathrm{P} 2 \mathrm{~m}$ responses. The peak latencies 369 of the $\mathrm{N} 1 \mathrm{~m}$ and $\mathrm{P} 2 \mathrm{~m}$ were calculated as the time instants when the 370 noise-normalized current estimates reached their maximum values 371 within the respective time windows of 110-170 ms and 190-310 ms. 372 For visualization purposes, dSPM estimates for the N1m and P2m re- 373 sponses were grand-averaged across subjects and conditions. Addition- 374 ally, grand-averaged dSPM estimates for the sustained field were 375 calculated as mean values in the time range of $400-560 \mathrm{~ms}$.

376

\section{Region of interest analysis}

Regions of interest (ROI) were determined by dividing the dSPM ac- 378 tivation areas into subregions on the basis of an anatomical parcellation 379 following the Desikan-Killiany-Tourville atlas (see Fig. 5; Desikan et al., 380 2006). Activations were analyzed in the following brain areas: the trans- 381 verse temporal gyrus (TTG), the superior temporal gyrus (STG), the su- 382 perior temporal sulcus (STS), the supramarginal gyrus (SMG), the 383 insula, the pars opercularis of the inferior frontal gyrus (POp), and the 384 precentral sulcus (PCS). The TTG and STG were combined into the 385 same ROI (TTG + STG). Because of the lack of individual structural 386 MRI data, the ROIs represent only approximations of the corresponding 387 brain areas. The original MNEs without noise normalization were aver- 388 aged over the source locations to obtain a time course of current 389 strength for each ROI. The mean currents within the ROIs were obtained 390 by averaging the time courses of the currents using a 40-ms time win- 391 dow centered at the peaks of the $\mathrm{N} 1 \mathrm{~m}$ and $\mathrm{P} 2 \mathrm{~m}$ responses. The peak la- 392 tencies were calculated as the time instants when the time courses of 393 the currents exhibited their maximum values within a 110-170-ms 394 time interval for the $\mathrm{N} 1 \mathrm{~m}$ and a 190-310-ms time interval for the 395 P2m response. For responses to words and sentences, the mean currents 396 were averaged over the time interval of 400-560 ms.

Dipole modeling

The single equivalent current dipole (ECD) was used to estimate the 399 source locations of the $\mathrm{N} 1 \mathrm{~m}$ and $\mathrm{P} 2 \mathrm{~m}$ responses. The ECDs were 400 modeled separately in each hemisphere by using a set of 12 gradiometer 401 pairs over each temporal region. A spherical model was used to estimate 402 the conductivity of the head. The ECD analysis was performed with the 403 Elekta Neuromag xFit Source Modeling Software.

\section{Statistical analyses}

405

The data from the behavioral and MEG measurements were ana- 406 lyzed using repeated-measures analysis of variance (ANOVA). Mauchly 407 sphericity tests were run, and Greenhouse-Geisser-corrected $p$ values Q6 and epsilons $(\varepsilon)$ were reported when the assumption of sphericity 409 was violated. For behavioral data, a $3 \times 3$ ANOVA was carried out, 410 with the within-subject factors of complexity (vowel/word/sentence) 411 and condition (degraded \& non-intelligible, i.e. 1st distorted; non- 412 degraded \& intelligible, i.e. undistorted; degraded \& intelligible, i.e. 413 2nd distorted). In the gradiometer analysis, the transient responses for 414 vowels, words and sentences were analyzed in separate $2 \times 3$ ANOVAs 415 (hemisphere $\times$ condition). Separate ANOVAs were used because the 416 SNR was very low for the responses to words and sentences especially 417 in the posterior and anterior channels, and therefore, including all the 418 complexity levels in the same ANOVA would have required the rejection 419 of a large number of subjects. To study the interactions between condi- 420 tion and complexity as well as the main effect of complexity, an 421 
additional analysis was made for the responses measured from the medial channels by including the transient responses to vowels, words and sentences in the same ANOVA. The mean currents during the transient responses also were investigated in separate $2 \times 3$ ANOVAs (hemisphere $\times$ condition) for vowels, words and sentences. This was because the number and shape of the ROIs determined using dynamic statistic map estimates (dSPM) varied between complexity levels. Similarly as in the gradiometer analysis, the interactions between condition and complexity as well as the main effect of complexity were studied by conducting an additional analysis where the responses to vowels, words and sentences were included in the same ANOVA table. This analysis was restricted to a subset of four ROIs (TTG + STG, SMG, STS and insula) that showed the highest SNR for sentences on the basis of the dSPM estimates. These ROIs were selected since they overlapped with the brain regions that showed the highest SNR also for vowels and words. Sustained fields elicited by words and sentences were included in a corresponding $2 \times 2 \times 3$ ANOVA (complexity $\times$ hemisphere $\times$ condition). The effects of intelligibility and speech degradation on the cortical activity measures were analyzed by post-hoc (Newman-Keuls) comparisons of the conditions. If the responses to the first and the second presentations of the distorted stimuli were unequal, the response was assumed to reflect intelligibility. If the responses to the first and the second presentations were equal with each other, but of a different magnitude than the response to the undistorted stimuli, it is likely that these differences reflect sensitivity to the acoustic structure of the stimulus.

\section{Results}

\section{The behaviorally measured intelligibility of the stimuli}

Intelligibility (defined as the proportion of correct identifications) was $98.6 \%( \pm 0.5 \%)$ for the undistorted vowels, words and sentences. As depicted in Fig. 2, the overall intelligibility was lower for the first presentation of the distorted stimuli than for the second presentation, increasing from $25.7 \pm 2.5 \%$ to $45.7 \pm 2.7 \%(F(1,21)=575.7, \varepsilon=0.7$, $p<0.001)$. This increase in intelligibility by 20 percentage points for acoustically identical stimuli demonstrates how a single presentation of intact speech material can alter the subject's ability to comprehend distorted speech.

The intelligibility of the undistorted stimuli was high for all complexity levels: $97.6 \%$ ( $\pm 0.8 \%$ ) for sentences, $98.8 \%$ ( $\pm 0.5 \%$ ) for words, and $99.4 \%( \pm 0.3 \%)$ for vowels. The magnitude by which the presentation of the undistorted stimuli increased the intelligibility of the distorted stimuli depended on the complexity level $(F(4,60)=27.1$; $p<0.001$ ). This increase was 33.8 percentage points for sentences (from $31.0 \pm 4.4 \%$ to $64.9 \pm 4.6 \% ; p<0.001$ ), 25.9 percentage points for words (from $19.1 \pm 3.9 \%$ to $45.1 \pm 3.7 \% ; p<0.001$ ) and, somewhat surprisingly, there was no improvement of vowel intelligibility (from $26.8 \pm 3.0 \%$ to $27.1 \pm 2.5 \%, p=$ n.s.). Thus, it appears that the complexity of the stimuli had a considerable effect on how well the subject was able to comprehend the stimulus, with intelligibility increasing with stimulus complexity.

\section{Transient responses}

\section{Amplitudes}

As depicted in Fig. 3, all complexity levels elicited prominent $\mathrm{N} 1 \mathrm{~m}$ and $\mathrm{P} 2 \mathrm{~m}$ responses in both hemispheres. Fig. 4 shows the peak amplitudes, peak latencies, and mean currents for these transient responses. In anterior areas, the $\mathrm{N} 1 \mathrm{~m}$ amplitude increased from $23.6 \pm 3.0 \mathrm{fT} / \mathrm{cm}$ as elicited by the undistorted vowels to $30.5 \pm 4.8 \mathrm{fT} / \mathrm{cm}$ and $33.9 \pm$ $5.3 \mathrm{fT} / \mathrm{cm}$ as elicited by the first and the second presentations of the distorted vowels, respectively $(F(1,16)=11.2, \varepsilon=0.6, p<0.01)$. This effect of speech distortion was hemispherically asymmetric $(F(1,18)=$ 8.3, $\varepsilon=0.7, p<0.01$ ), and post-hoc tests revealed that the $\mathrm{N} 1 \mathrm{~m}$
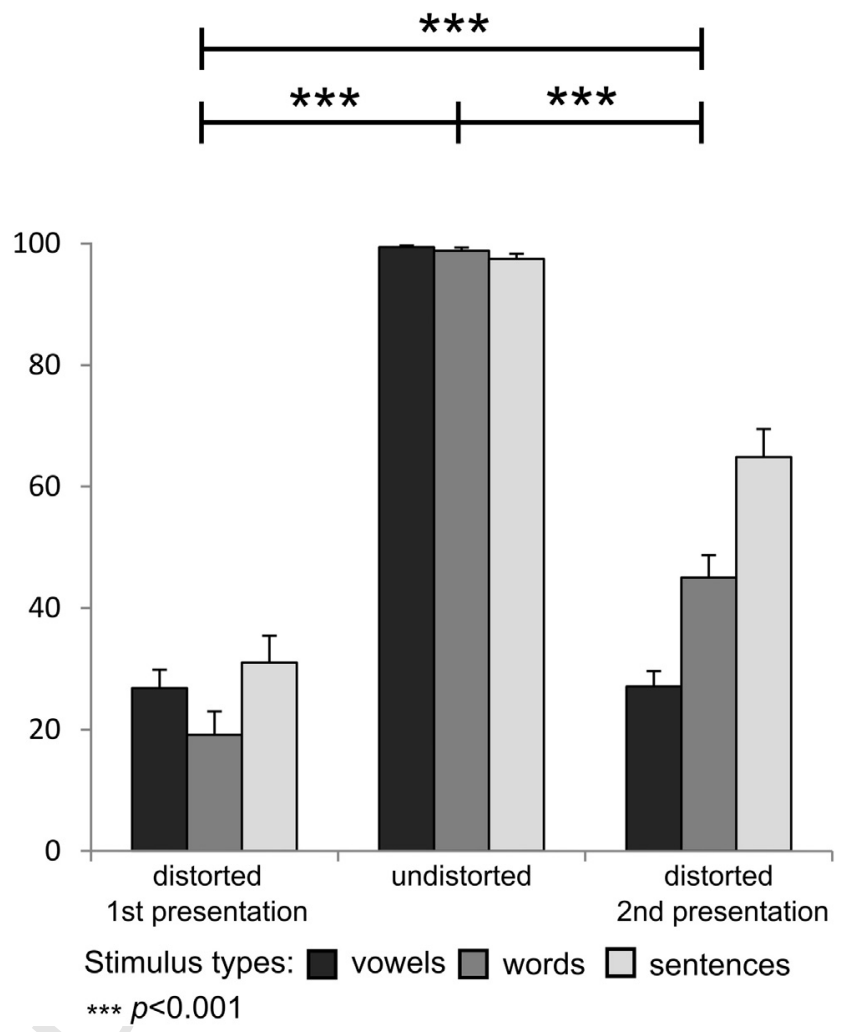

Fig. 2. Behavioral results. At their first presentation, distorted stimuli were difficult to understand (mean subjective intelligibility rating $=25.7 \%$ ). After an intervening presentation of the same stimuli in an undistorted form (98.6\%), the intelligibility of the words and sentences increased considerably (45.7\%). Error bars indicate SEM. Significance stars indicate differences between intelligibilities of speech stimuli in their three presentations (averages over complexity levels).

amplitude was stronger for the distorted vowels only in the right hemi- 483 sphere (1st distorted: $36.0 \pm 5.4 \mathrm{fT} / \mathrm{cm}, 2$ nd distorted: $40.4 \pm 6.3 \mathrm{fT} / \mathrm{cm}, 484$ undistorted: $23.7 \pm 2.9 \mathrm{fT} / \mathrm{cm}, p<0.001)$. In medial and posterior areas, 485 the distorted and the undistorted vowels elicited $\mathrm{N} 1 \mathrm{~m}$ amplitudes of 486 equal magnitude. The magnitude of the $\mathrm{N} 1 \mathrm{~m}$ amplitude elicited by 487 words showed hemispheric asymmetry $(F(2,24)=3.1, p<0.07)$ in 488 the anterior channels, where the right-hemispheric amplitude was 489 stronger for the second presentation of the distorted words $(22.2 \pm 490$ $3.1 \mathrm{fT} / \mathrm{cm})$ than for their first presentation $(17.8 \pm 3.4 \mathrm{fT} / \mathrm{cm}, p<0.05) 491$ as well as for the undistorted words $(13.7 \pm 1.8 \mathrm{fT} / \mathrm{cm}, p<0.001) .492$ No significant differences were found between the magnitudes of the 493 left-hemispheric N1m responses to words. Hemispheric asymmetry 494 was also found in the $\mathrm{N} 1 \mathrm{~m}$ amplitudes in the posterior channels 495 $(F(2,22)=6.7, p<0.01)$ : only the right-hemispheric $\mathrm{N} 1 \mathrm{~m}$ response 496 increased from $10.1 \pm 2.0 \mathrm{fT} / \mathrm{cm}$ for the undistorted words to 497 $17.3 \pm 2.7 \mathrm{fT} / \mathrm{cm}$ for the second presentation of the distorted words 498 $(p<0.05)$. The amplitudes of the N1m responses elicited by sentences 499 were of equal magnitude in all cases. In the medial channels, vowels 500 $(34.8 \pm 3.6 \mathrm{fT} / \mathrm{cm})$ elicited $10.6 \mathrm{fT} / \mathrm{cm}$ stronger response than words 501 $(24.2 \pm 2.2 \mathrm{fT} / \mathrm{cm}, p<0.001)$ and $13.6 \mathrm{fT} / \mathrm{cm}$ stronger response than 502 sentences $(21.2 \pm 1.8 \mathrm{fT} / \mathrm{cm}, p<0.001$; see Fig. 4). The $\mathrm{P} 2 \mathrm{~m} 503$ amplitudes were insensitive to intelligibility, speech degradation, and 504 complexity.

Latencies

506

The distorted vowels, words, and sentences resulted in $\mathrm{N} 1 \mathrm{~m}$ and 507 P2m responses which had a longer peak latency than the responses elic- 508 ited by the corresponding undistorted versions of the stimuli. In anterior 509 channels, this delay was $7.2 \mathrm{~ms}$ for vowels, $9.1 \mathrm{~ms}$ for words and $12.0 \mathrm{~ms} 510$ for sentences (see Table 1 for details). For vowels, the delay was 511 hemispherically asymmetric $(F(1,19)=4.5, \varepsilon=0.7, p<0.05)$ : in the 512 
left hemisphere
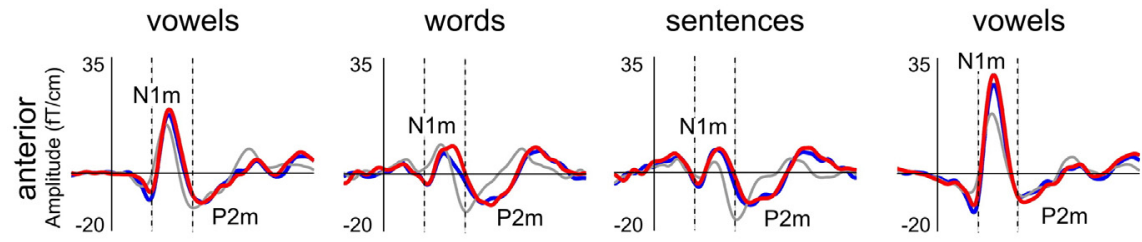

right hemisphere
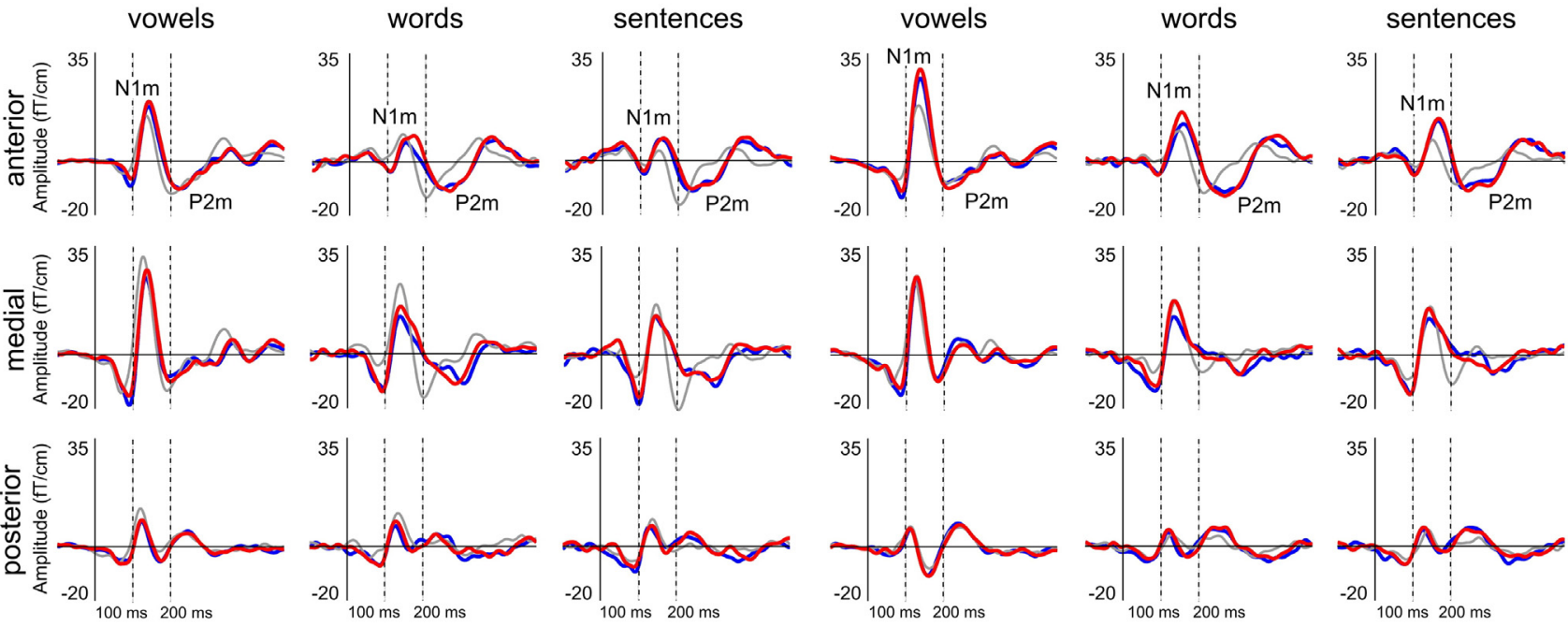

1st presentation of distorted stimuli

$\square$ presentation of undistorted stimuli

2nd presentation of disrorted stimuli

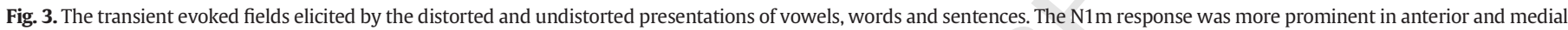

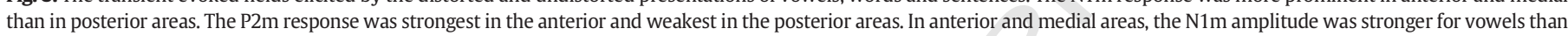

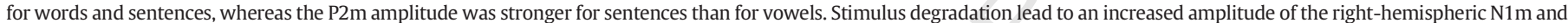

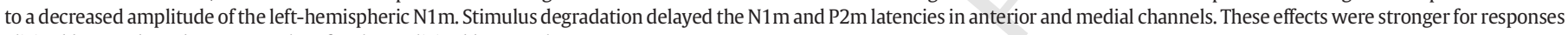
elicited by words and sentences than for those elicited by vowels.

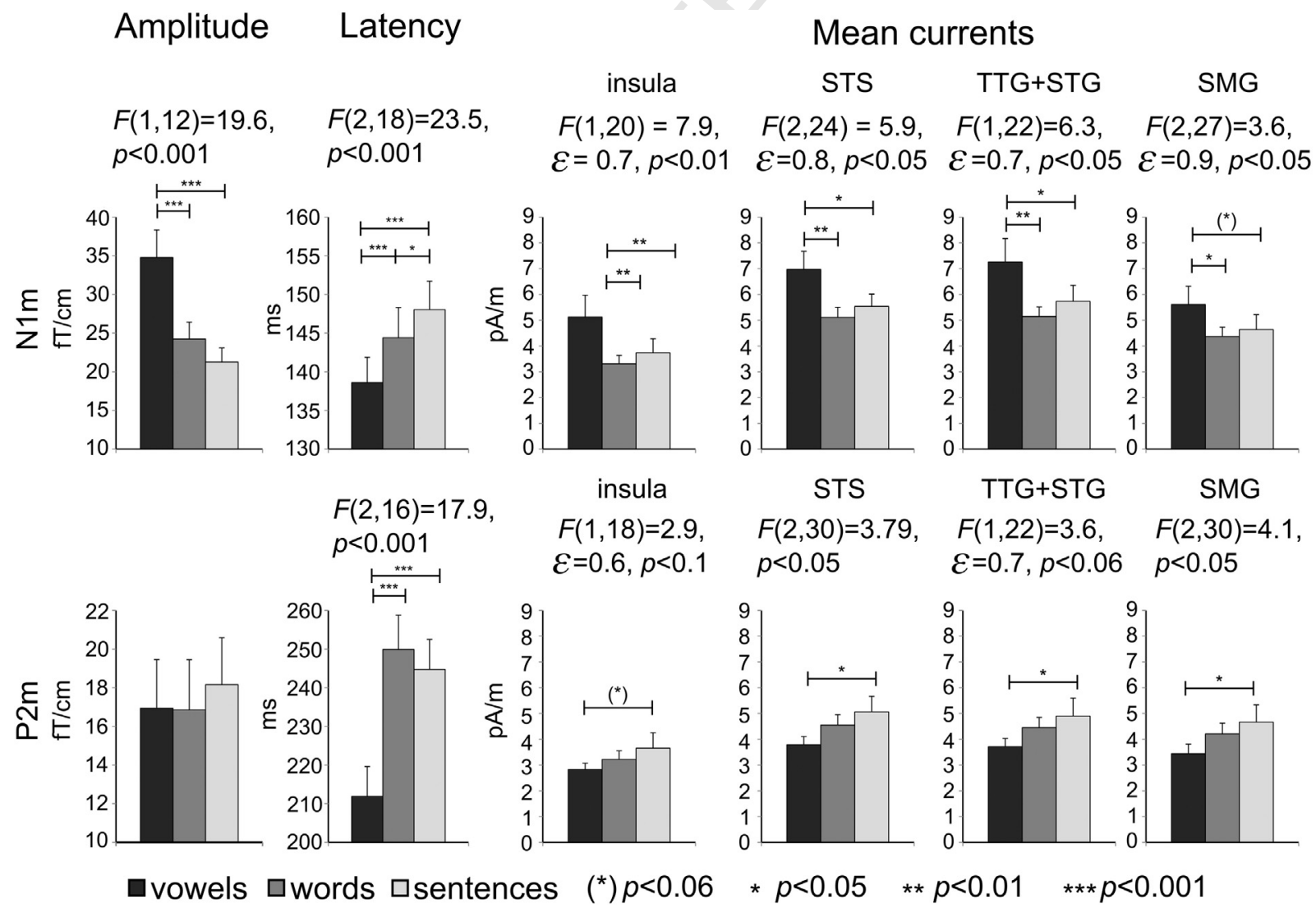

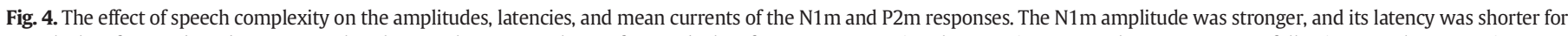

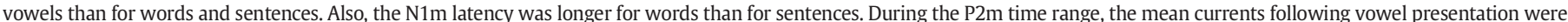

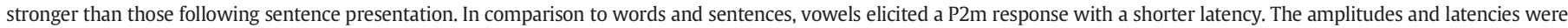

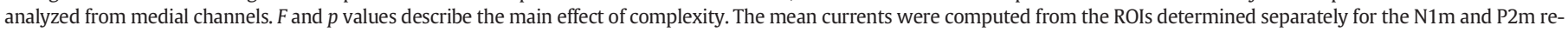
sponses on the basis of the dSPM activation areas for sentences shown in Fig. 5. Error bars indicate SEM. 
t Q1 Table 1

t1.2 The N1m and P2m latencies in three different conditions. Distortion of the stimuli delayed the responses bilaterally. The results for vowels, words and sentences were computed using separate ANOVAs with different number of subjects. The responses for the medial channels were additionally analyzed in the same ANOVA. However, no interaction between complexity and degradation was found in this analysis. The main effect of complexity is shown in Fig. 4.

\begin{tabular}{|c|c|c|c|c|c|c|c|}
\hline & $F$ & $d f 1$ & $d f 2$ & $p$ & 1st distorted & Undistorted & $\begin{array}{l}\text { 2nd } \\
\text { distorted }\end{array}$ \\
\hline \multicolumn{8}{|l|}{ N1m latency } \\
\hline \multicolumn{8}{|l|}{ Anterior } \\
\hline Vowels & 8.3 & 2 & 28 & $<0.01$ & $145.8 \pm 2.2$ & $139.8 \pm 2.8$ & $148.1 \pm 2.2$ \\
\hline Words & 7.2 & 2 & 24 & $<0.01$ & $149.9 \pm 2.9$ & $141.4 \pm 2.9$ & $151.1 \pm 3.7$ \\
\hline Sentences & 9.3 & 2 & 14 & $<0.01$ & $157.8 \pm 2.5$ & $144.7 \pm 3.3$ & $155.7 \pm 3.8$ \\
\hline \multicolumn{8}{|l|}{ Medial } \\
\hline Vowels & 11.5 & 2 & 30 & $<0.001$ & $137.3 \pm 2.8$ & $132.7 \pm 2.4$ & $140.5 \pm 2.3$ \\
\hline Words & 3.3 & 2 & 24 & $<0.06$ & $146.2 \pm 4.1$ & $138.9 \pm 2.8$ & $145.9 \pm 3.7$ \\
\hline Posterior & & 2 & & & & & \\
\hline Vowels & 3.6 & 2 & 24 & $<0.05$ & $138.5 \pm 2.9$ & $134.9 \pm 4.2$ & $141.3 \pm 3.0$ \\
\hline \multicolumn{8}{|l|}{ P2m latency } \\
\hline \multicolumn{8}{|l|}{ Anterior } \\
\hline Vowels & 4.4 & 2 & 28 & $<0.05$ & $230.3 \pm 5.6$ & $216.8 \pm 5.7$ & $231.0 \pm 4.4$ \\
\hline Words & 21.9 & 2 & 24 & $<0.001$ & $263.9 \pm 7.1$ & $220.6 \pm 5.8$ & $263.7 \pm 7.3$ \\
\hline Sentences & 13.7 & 2 & 20 & $<0.001$ & $250.6 \pm 9.2$ & $213.4 \pm 5.4$ & $263.3 \pm 10.0$ \\
\hline \multicolumn{8}{|l|}{ Medial } \\
\hline Words & 16.4 & 2 & 26 & $<0.001$ & $264.8 \pm 10.4$ & $217.4 \pm 5.4$ & $261.0 \pm 9.7$ \\
\hline Sentences & 5.8 & 2 & 20 & $<0.05$ & $251.5 \pm 10.4$ & $220.6 \pm 7.4$ & $263.0 \pm 12.3$ \\
\hline \multicolumn{8}{|l|}{ Posterior } \\
\hline Words & 4.2 & 2 & 14 & $<0.05$ & $245.1 \pm 11.9$ & $212.9 \pm 8.9$ & $248.7 \pm 15.7$ \\
\hline
\end{tabular}

to the distorted counterparts of the stimuli (distorted: mean $z=59.2 \pm 551$ $1.9 \mathrm{~mm}$, undistorted: $z=49.3 \pm 3.5 \mathrm{~mm} ; F(2,8)=5.9, p<0.05)$. The 552 source location of the P2m elicited by vowels was dependent on condi- 553 tion (i.e. first distorted, undistorted, second distorted) and hemisphere 554 $(F(1,9)=6.5, \varepsilon=0.6, p<0.05)$ : In the right hemisphere, the second pre- 555 sentation of the distorted vowels elicited a more medial P2m response 556 $(x=41.5 \pm 4.3 \mathrm{~mm})$ than the undistorted vowels $(x=54.6 \pm 557$ $2.1 \mathrm{~mm}, p<0.001)$ and the first presentation of the distorted vowels 558 $(x=50.4 \pm 1.9 \mathrm{~mm}, p<0.05$ ), but this medial shift was not observed 559 in the left hemisphere. In general, the source locations of the N1m re- 560 sponses for vowels and sentences were more anterior in the right 561 (vowels: $y=15.0 \pm 2.2 \mathrm{~mm}$; sentences: $y=5.2 \pm 1.7 \mathrm{~mm}$ ) than in 562 the left hemisphere (vowels: $y=4.1 \pm 2.5 \mathrm{~mm}, F(1,12)=15.2,563$ $p<0.01$; sentences: $y=-2.8 \pm 2.8 \mathrm{~mm}, F(1,8)=9.6, p<0.05)$.

\section{Mean currents}

A number of brain regions exhibited sensitivity to the intelligibility 566 of speech during the N1m time range (see Fig. 5). In the left- 567 hemispheric TTG + STG, SMG, STS, insula, and PSC, cortical activity in- 568 creased from $2.2-4.4 \mathrm{pA} / \mathrm{m}$ elicited by the first presentation of the 569 distorted vowels to $3.8-7.9 \mathrm{pA} / \mathrm{m}$ elicited by the presentation of the un- 570 distorted vowels and to $3.0-6.2 \mathrm{pA} / \mathrm{m}$ elicited by the second presenta- 571 tion of the distorted vowels. A comparable intelligibility effect was 572 also found in the right-hemispheric TTG + STG, STS and insula. In 573 these brain areas, the second presentation of the distorted vowels 574 (4.4-7.9 $\mathrm{pA} / \mathrm{m}$ ) yielded on average $1.4 \mathrm{pA} / \mathrm{m}$ stronger currents than 575 the first presentation of the same vowels (3.5-6.2 pA/m; see Fig. 5 for 576 statistical results). For sentences, the left-hemispheric insula showed 577 sensitivity to speech intelligibility, with the unintelligible sentences 578 resulting in $1.0 \mathrm{pA} / \mathrm{m}$ weaker currents (1st distorted: $3.3 \mathrm{pA} / \mathrm{m}$ ) than 579 the intelligible ones (2nd distorted: $4.3 \mathrm{pA} / \mathrm{m}$, undistorted: $4.1 \mathrm{pA} / \mathrm{m}$ ). 580 In the left-hemispheric POp, speech degradation decreased the mean 581 currents from $5.0 \mathrm{pA} / \mathrm{m}$ elicited by the presentation of the undistorted 582 vowels to $2.3 \mathrm{pA} / \mathrm{m}$ and $3.0 \mathrm{pA} / \mathrm{m}$ elicited by the first and the second 583 presentations of the distorted vowels, respectively. For words, a corre- 584 sponding effect was found in the left-hemispheric STS where brain ac- 585 tivity decreased from $6.5 \mathrm{pA} / \mathrm{m}$ to $4.9 \mathrm{pA} / \mathrm{m}$ (1st distorted) and 586 $4.4 \mathrm{pA} / \mathrm{m}$ (2nd distorted) as a result of speech degradation. As illustrat- 587 ed in Fig. 4, the mean currents during the N1m time range were on av- 588 erage $1.5 \mathrm{pA} / \mathrm{m}$ stronger for vowels $(5.1-7.3 \mathrm{pA} / \mathrm{m})$ than for words 589 (3.3-5.1 pA/m) and sentences (3.7-5.7 pA/m) in the TTG + STG, SMG, 590 STS and insula, whereas the responses to words were of equal magni- 591 tude to those elicited by sentences.

During the P2m time range, speech degradation affected cortical ac- 593 tivity in the auditory cortex and surrounding areas. In the left hemi- 594 sphere, the TTG + STG, SMG, STS and insula showed sensitivity to 595 acoustic degradation in that speech degradation decreased the mean 596 currents from 4.1-5.0 $\mathrm{pA} / \mathrm{m}$ to $2.1-3.3 \mathrm{pA} / \mathrm{m}$ for vowels and from 597 5.0-7.2 $\mathrm{pA} / \mathrm{m}$ to $3.8-5.3 \mathrm{pA} / \mathrm{m}$ for sentences (currents for 1 st and 2 nd 598 distorted presentations averaged). With word stimuli, sensitivity to 599 speech degradation was found in the left-hemispheric TTG + STG and 600 insula where the mean currents decreased from $4.2-5.9 \mathrm{pA} / \mathrm{m}$ to 601 $3.1-4.7 \mathrm{pA} / \mathrm{m}$. In the right hemisphere, cortical activity decreased from 602 $3.8-4.1 \mathrm{pA} / \mathrm{m}$ to $2.9-3.3 \mathrm{pA} / \mathrm{m}$ as a result of vowel degradation in the 603 STS and SMG. In the case of words and sentences, the right hemisphere 604 showed no sensitivity to speech degradation. As illustrated in Fig. 4, the 605 mean currents increased from $2.8-3.8 \mathrm{pA} / \mathrm{m}$ to $3.7-5.1 \mathrm{pA} / \mathrm{m}$ (on aver- 606 age $1.1 \mathrm{pA} / \mathrm{m}$ ) when responses to vowels were contrasted to those elic- 607 ited by sentences in the TTG + STG, SMG, and STS.

Sustained fields

609

Amplitudes

610

The mean amplitude of the sustained field was on average $3.7 \mathrm{fT} / \mathrm{cm} 611$ stronger for the distorted $(16.5-18.6 \mathrm{fT} / \mathrm{cm})$ than for the undistorted 612 words (12.9-14.3 fT/cm) in the sensorimotor, occipitotemporal and 613 


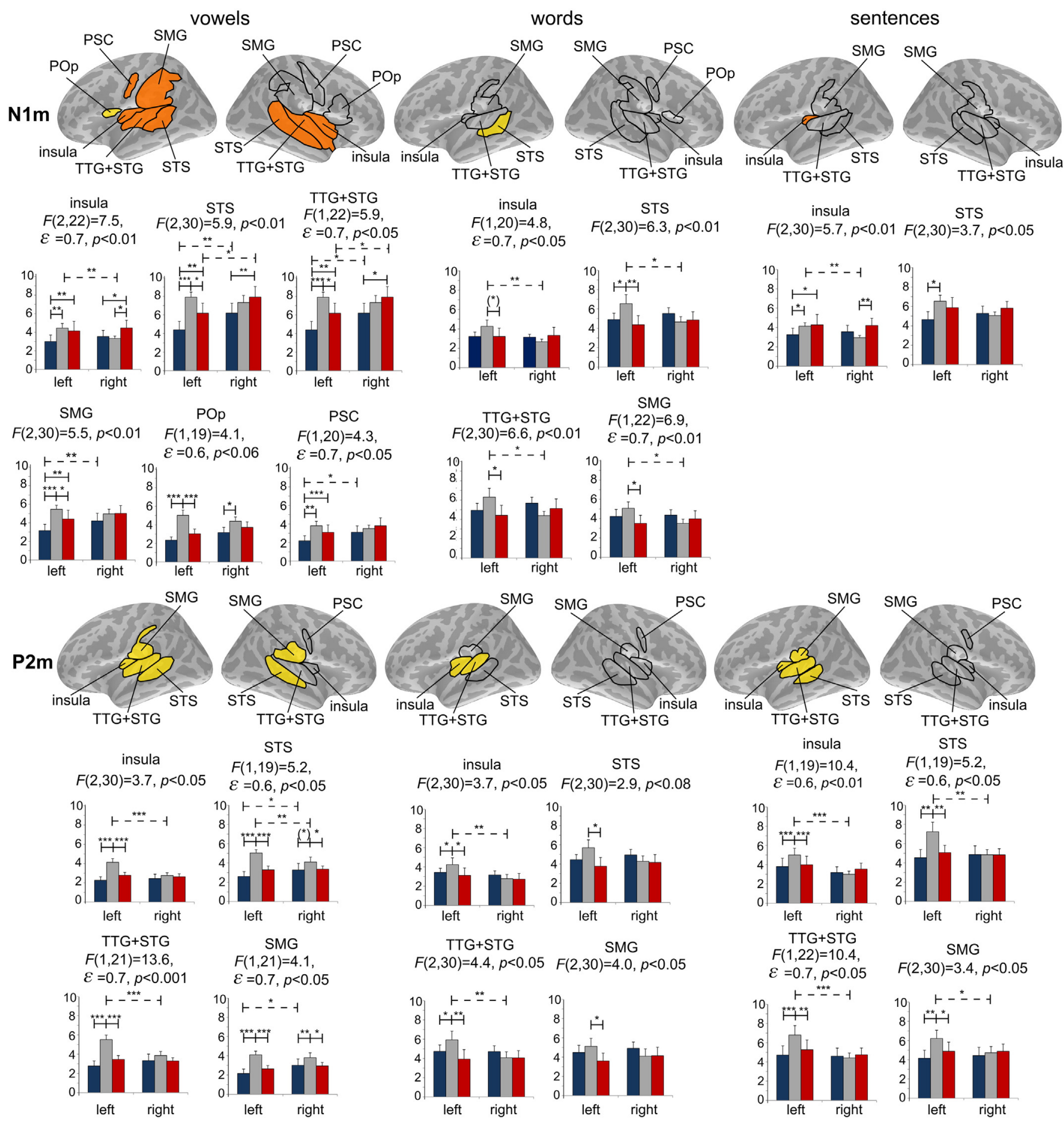

ROls:

Conditions:

$\square$ Sensitive to speech degradation $\square$ 1st presentation of distorted stimuli - - Difference between hemispheres

$\left({ }^{*}\right) p<0.07$ $\square$ Sensitive to speech intelligibility

$\square$ presentation of undistorted stimuli
$\square$ 2nd presentation of disrorted stimuli

$* p<0.05$

$* * p<0.01$

$* * * p<0.001$

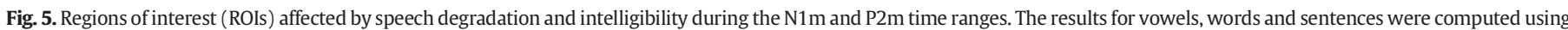

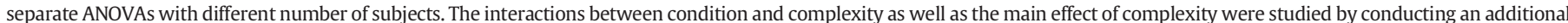

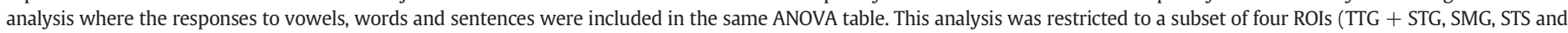

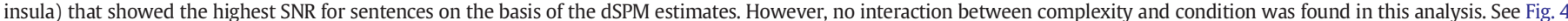

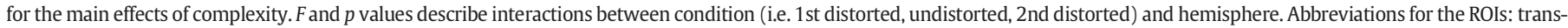

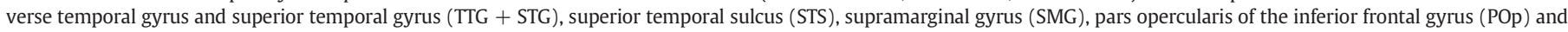
precentral sulcus (PCS). Error bars indicate SEM. 

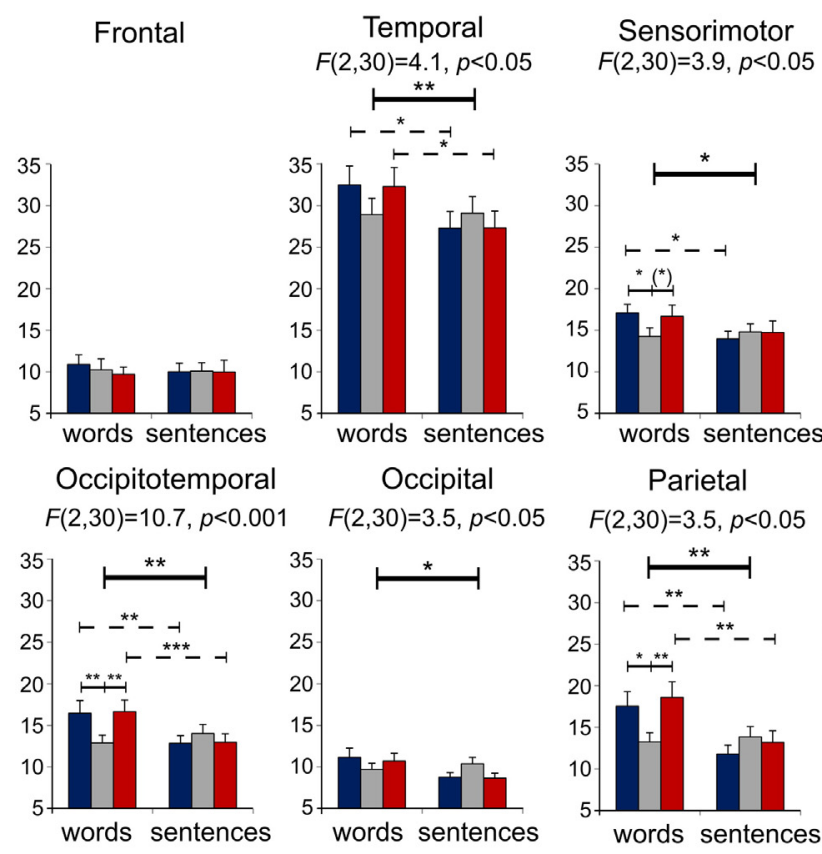

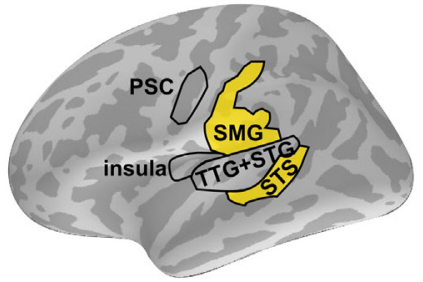

SMG

$F(2,30)=6.7, p<0.01$

TTG+STG

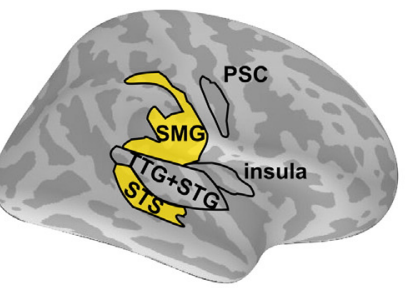

STS
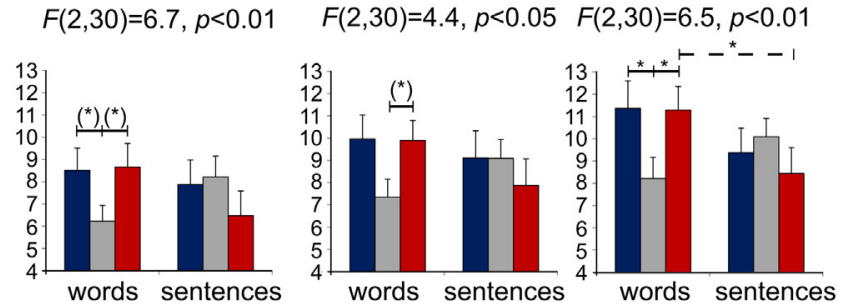

Difference between complexity levels over all conditions

- - Difference between same conditions between complexity levels

Difference between conditions within complexity level

$\square$ 1st presentation of distorted stimuli

$\square$ presentation of undistorted stimuli

$\square$ 2nd presentation of disrorted stimuli

$\left({ }^{*}\right) p<0.07$

$* p<0.05$

$* * p<0.01$

$* * * p<0.001$

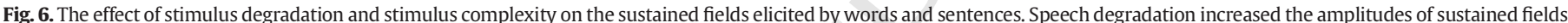

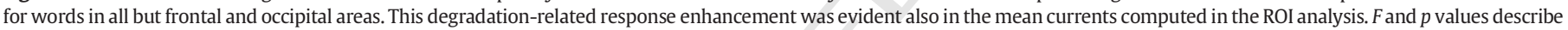

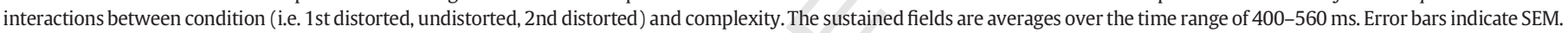

parietal areas (see Fig. 6). Further, the mean amplitudes were equally strong for the first and the second presentations of the distorted words. Words elicited on average $2.3 \mathrm{fT} / \mathrm{cm}$ stronger sustained fields (10.5-31.2 fT/cm) compared to sentences $(9.3-27.9 \mathrm{fT} / \mathrm{cm})$ in all but the frontal area. In the temporal, occipitotemporal and parietal areas, this effect was due to the stronger sustained fields for the distorted words $(16.5-32.5 \mathrm{fT} / \mathrm{cm})$ when compared to the sustained field elicited by the distorted sentences $(11.8-27.3 \mathrm{fT} / \mathrm{cm})$. In the sensorimotor area, the first presentation of the distorted words resulted in a $3.1 \mathrm{fT} / \mathrm{cm}$ stronger sustained field $(17.1 \mathrm{fT} / \mathrm{cm})$ compared to that elicited by the first presentation of the distorted sentences $(14.0 \mathrm{fT} / \mathrm{cm})$.

\section{Mean currents}

The mean currents during the sustained field for words were sensitive to speech degradation in the SMG and STS, with the first and the second presentations of the distorted stimuli resulting in $2.7 \mathrm{pA} / \mathrm{m}$ stronger responses (8.5-11.4 pA/m) compared to the responses elicited by the undistorted stimuli $(6.2-8.2 \mathrm{pA} / \mathrm{m})$. In the TTG + STG, the distorted words elicited $2.5 \mathrm{pA} / \mathrm{m}$ stronger mean current than the undistorted words $(7.4 \mathrm{pA} / \mathrm{m})$ only at their second presentation $(9.9 \mathrm{pA} / \mathrm{m})$. The results are summarized in Fig. 6 .

\section{Discussion}

We studied how speech comprehension is modified by varying the level of intelligibility (i.e. by using acoustically distorted and undistorted stimuli) and stimulus complexity (i.e. by using isolated vowel sounds, words, and sentences). In both the behavioral and MEG experiments, the subject was first presented with a set of the distorted stimuli, then with the undistorted (intact) version of the same set, and finally the set of distorted stimuli was presented once more. We were particularly interested in comparing the responses to the two instances of the distorted stimulus sets which were acoustically identical. While the intelligibility of the undistorted stimuli was 99\%, the overall intelligibil- 644 ity of the distorted speech sounds increased from $26 \%$ at the first pre- 645 sentation to $46 \%$ at the second. Thus, only a single intervening 646 exposure to an intact (undistorted) version of the stimulus was suffi- 647 cient to render the originally incomprehensible (distorted) speech 648 sounds comprehensible to the subjects. Interestingly, we also found 649 that intelligibility increased considerably as a function of stimulus com- 650 plexity, indicating the importance of both word- and sentence-level in- 651 formation to speech comprehension under adverse acoustic conditions. 652 Speech intelligibility was reflected in cortical activity already at laten- 653 cies of 130-160 ms, suggesting that top-down modulations from 654 higher-order cortical areas take place very rapidly. Speech complexity 655 correlated with cortical activity at latencies of $200-270 \mathrm{~ms}$.

Effects of top-down information and stimulus complexity on behaviorally 657 measured speech intelligibility

The distorted stimuli were difficult to understand at their first pre- 659 sentation (average intelligibility across the three complexity levels: 660 $26 \%$ ), but after an intervening presentation of the same stimuli in the 661 undistorted, intelligible form (99\%), the comprehensibility of the 662 distorted stimuli increased considerably (46\%). This result corroborates 663 the findings of our recent attempt on this particular issue (Tiitinen et al., 664 2012) and that of Hannemann et al. (2007) who found that hearing 665 low-resolution, initially unintelligible nouns in intact form renders 666 them more likely to be perceived as intelligible in a consecutive test se- 667 quence. It is unlikely that these perceptual changes resulted from the re- 668 peated presentation of the distorted stimuli since there was a gap of 669 several minutes ( $10 \mathrm{~min}$ for vowels, $4 \mathrm{~min}$ for words, and $11 \mathrm{~min}$ for 670 sentences) between the distorted presentations. Therefore, it is improb- 671 able that the subject could have been drawing on any echoic or short- 672 term memory resources in this case. This conclusion is supported by 673 the results obtained in the MEG measurements: stimulus repetition 674 
within a time window of seconds usually leads to diminished brain responses, that is, to an opposite pattern to the one observed in this study. As also the contaminating effects of acoustic variation in the stimulation can be ruled out as an explanation for the performance enhancement in these experimental paradigms, it appears that only a single encounter with the intact stimulus significantly facilitates the identification of its distorted counterpart, probably by activating (Diamond and Rozin, 1984; Dorfman, 1994; Forster et al., 1990) and/or modifying (Morton, 1979) corresponding preexisting memory representations or by creating new memory traces (for a review, see Bodner and Masson, 2014). This kind of effect of a stimulus on the response to a later stimulus is referred to as priming (Tulving and Schacter, 1990), and it has typically been examined in word-stem completion (WSC) tests (Tulving et al., 1982). In WSC tests, the subject is first presented with a list of words, and after a delay (typically from several minutes to several hours) he/she is given word stems that have multiple possible completions. Priming occurs when the subject completes the stem more often according to words that had been presented to him/her earlier than according to words that were not presented previously. Priming effects have been reported for different types of stimuli, including pseudowords (Bowers, 1996), familiar and unfamiliar objects (Diamond, 1990), and visual patterns (Ahissar and Hochstein, 2004; Tallon-Baudry et al., 1997). Our results parallel these findings by suggesting that perception relies not only on incoming sensory information but also on facilitative memory-related cognitive processes. Further, this top-down support can produce dramatic and rapid changes to the percept when the eliciting stimulus is under extreme forms of distortion and when not enough bottom-up acoustic cues are available to achieve comprehension.

The distorted vowels were difficult to understand (27\%), both before and after the presentation of their undistorted and intelligible counterparts. In contrast, the initially challenging words (19\%) became considerably more comprehensible (45\%) following the presentation of the undistorted words. This effect was even more pronounced for the distorted sentences whose intelligibility increased from $31 \%$ to $65 \%$. Thus, the comprehension of the distorted speech stimuli appears to become easier the more complex the signal is. The increase of intelligibility for 48 sentences in this study was 15 percentage points smaller than the increase achieved with 120 sentences in our previous study (Tiitinen et al., 2012). One possible reason for this is that the sentence set in our previous study was constructed from only seven starting words, three sentence stubs, and four ending words, whereas in the recent study each sentence was unique. Thus, it seems that decreasing the information content of the stimulus set and repeating the same words and sentence stubs increases the priming effect, making the sentences easier to recognize in their distorted form.

The current data merely suggests that the retrieval on bottom-up information from degraded speech is enhanced by memory-driven topdown processes and, at least if low-frequency information is still present in the signal, this effect increases as a function of stimulus complexity. However, it remains unclear which particular aspects of complexity the increase in intelligibility relies on. A possible explanation would be syntactic (Miller and Isard, 1963), semantic (Boothroyd and Nittrouer, 1988; Bradlow and Alexander, 2007; Kalikow et al., 1977; Obleser et al., 2007; Smiljanic and Sladen, 2013; Valentini-Botinhao and Wester, 2014), and lexical influences (McClelland et al., 2006) that have shown to exert contextual influences over speech decoding and intelligibility. Our observations coupled with these previous ones support many of the current psycholinguistic theories, such as the TRACE model (McClelland and Elman, 1986) and the distributed coherent model (Marslen-Wilson, 1987), according to which the mapping of sensory input to stored speech representations occurs in a cascading manner as the speech stream evolves, and the number of possible lexical candidates is gradually reduced until recognition is achieved. This is nicely demonstrated in our experiment: speech intelligibility increases as information accumulates when vowels evolve into words, and words into sentences. Another aspect of speech complexity that may 741 have increased intelligibility is the temporal envelope of speech (i.e. 742 the acoustic power at a given time in a given frequency range; Peelle 743 and Davis, 2012). This contains cues for speech parsing on both the syl- 744 labic and phrasal levels (for reviewers, see Golumbic et al., 2012; Peelle 745 and Davis, 2012). These low-frequency fluctuations were still present in 746 the degraded signals of the current study, although distorted by their 747 harmonic frequencies. Replacing the signal waveform with rectangular 748 pulses in the USQ procedure clearly decreases the envelope information 749 but retains distinguishable "bursts" of energy. Since these bursts indi- 750 cate distinct syllables (Golumbic et al., 2012), they may have supported 751 parsing the signal into syllable-size packages, thereby increasing the in- 752 telligibility of words and sentences. Thus, it may be that less top-down 753 facilitation was required to render words and sentences intelligible 754 compared to vowels and, consequently, the intelligibility increased as 755 a function of stimulus complexity after priming.

The novelty of the experimental paradigm used here also points to 757 several issues that would need further clarification. First, the contribu- 758 tion of different aspects of speech complexity on intelligibility could 759 further be evaluated by studying whether a similar increase in intelligi- 760 bility can be achieved with other forms of distorted speech or with syn- 761 tactically violated sentences and syntactically correct meaningless 762 sentences. Second, it would be interesting to see whether the human 763 brain can dynamically tune the perceptual system to optimally process 764 degraded speech so that the repetition of distorted stimuli in itself in- 765 creases their intelligibility even without the intervening presentation 766 of their undistorted counterparts. However, it is unlikely that, in this 767 study, perceptual learning occurring during the first presentation of 768 the degraded stimuli would have resulted in such a dramatic increase 769 in intelligibility at the second presentation of the degraded stimuli. 770 This is supported by the results of Hannemann et al. (2007) who 771 found increase in the identification accuracy and changes in the related 772 brain responses only for distorted stimuli that had also been presented 773 in undistorted form, but not for stimuli presented only in distorted form. 774 An interesting question also is how the number of stimuli and the delay 775 between the distorted and undistorted presentations affect intelligibili- 776 ty and behavioral performances. Assuming that the memory system 777 probed with the current paradigm has a capacity limitation, increasing 778 the number of sentences and/or the intervening interval should at 779 some point lead to decreased performance.

In the current study, a number of cortical areas exhibited activation 782 during the N1m time range that could be associated with speech intel- 783 ligibility: the mean currents elicited by the distorted stimuli upon 784 their second presentation increased on average $34 \%$ as a result of the ex- 785 posure to their undistorted counterparts. In the case of vowel stimula- 786 tion, these areas included the transverse temporal gyrus (TTG) and 787 the superior temporal gyrus (STG; posterior STG in the left hemisphere; 788 STG and TTG studied within the same ROI), as well as the superior tem- 789 poral sulcus (STS; posterior STS in the left hemisphere), the posterior 790 insula, the left-hemispheric anterior supramarginal gyrus (SMG) and 791 the left-hemispheric inferior postcentral sulcus (PSC). A corresponding 792 effect was absent for words, and it was restricted to the posterior insula 793 for sentences. This poverty of effects in the case of words and sentences 794 was probably due to these stimuli eliciting overall much weaker re- 795 sponses, resulting in a decreased signal-to-noise ratio (SNR) compared 796 to the case when vowels were used as stimuli.

797

The more prominent $\mathrm{N} 1 \mathrm{~m}$ responses for the distorted signals upon 798 their second presentation suggests that speech processing is guided, 799 or at least modified, by auditory long-term memory representations al- 800 ready at very early processing stages, even in conditions where incom- 801 ing sounds are processed without attentional demands (given the 802 passive recording condition). Tentatively, this may be explained by a fil- 803 tering mechanism wherein the receptive fields of neurons are re- 804 
shaped at hierarchically multiple levels to "filter" certain features from noise (Jääskeläinen et al., 2007). Probably, the enhanced N1m reflects sensitivity to speech sounds, as suggested by studies that have documented a stronger $\mathrm{N} 1 \mathrm{~m}$ amplitude and/or a shorter $\mathrm{N} 1 \mathrm{~m}$ latency for speech sounds compared to non-speech sounds (for a review, see Salmelin, 2007). Because an enhancement of the $\mathrm{N} 1(\mathrm{~m})$ has also been reported when, for example, listeners are familiar with speech (Ylinen and Huotilainen, 2007), animal (Kirmse et al., 2009) and musical instrument sounds (Pantev et al., 2001), it may alternatively be that the stronger $\mathrm{N} 1 \mathrm{~m}$ reflects enhanced processing of behaviorally relevant sounds in general.

The robust intelligibility effects observed in the behavioral experiment lacked prominent correlates in terms of neuronal activity in time ranges after the $\mathrm{N} 1 \mathrm{~m}$. One reason for this might be that the resolution of MEG may not be suitable for measuring intelligibility-related brain activity when it spreads from the temporal cortex to other brain regions. Indeed, there is evidence that anterior and frontal brain sources may be too distant to be reliably picked up by MEG sensors, especially, if the subjects lean against the back wall of the measurement helmet (Marinkovic et al., 2004). Given that recent fMRI studies have found strong evidence for cortical activity associated with speech intelligibility (for a review, see Peelle et al., 2010), an obvious future extension of this study would be to use a modified version of the current experimental setup in an fMRI experiment.

\section{Neural correlates of sound degradation}

Acoustic degradation increased the right-hemispheric N1m amplitude for vowels by $36 \%$ on average and delayed bilaterally the latencies of both the N1m (by $6 \mathrm{~ms}$ for vowels, $8 \mathrm{~ms}$ for words, and $12 \mathrm{~ms}$ for sentences) and the $\mathrm{P} 2 \mathrm{~m}$ response (by $14 \mathrm{~ms}$ for vowels and by $40 \mathrm{~ms}$ for words and sentences) for all complexity levels. Evidence for cortical activations being sensitive to acoustic features during the $\mathrm{N} 1 \mathrm{~m}$ and $\mathrm{P} 2 \mathrm{~m}$ responses was also found in the ROI analysis. During the $\mathrm{N} 1 \mathrm{~m}$ time range, the mean currents associated with vowel processing were attenuated $47 \%$ by stimulus distortion in the left-hemispheric POp. During the $\mathrm{P} 2 \mathrm{~m}$ time range, speech degradation decreased left-hemispheric cortical activity, on average, by $41 \%$ for vowels and $25 \%$ for sentences in the TTG and in posterior parts of the STG (studied within the same ROI), the STS and the insula, as well as in the anterior SMG. For words, speech degradation decreased the mean currents by $25 \%$ in the TTG, posterior parts of the STG (studied within the same ROI) and the insula. In the right hemisphere, this attenuation effect was present only for vowels and remained restricted to the STS and the anterior SMG where the mean currents were $20 \%$ weaker for the distorted vowels.

The right-hemispheric increase of the amplitude of the $\mathrm{N} 1 \mathrm{~m}$ to the distorted vowels is in line with the results of previous studies using vowels and employing the same distortion method based on amplitude quantization as used here (Liikkanen et al., 2007; Miettinen et al., 2010, 2012). These studies suggested that the amplitude increase is related to a generation of new prominent frequency components by the nonlinear process utilized in the sound degradation. These additional harmonics possibly activate a larger number of neurons involved in the pitch extraction process. However, in the current study, acoustic degradation of words and sentences was not reflected in the N1m and P2m amplitudes, whereas in our previous study (Tiitinen et al., 2012), the amplitudes increased bilaterally for degraded sentences. A possible reason for this is that the responses were stronger in our previous study (amplitudes: N1m: 43-64 fT/cm vs. 20-24 fT/cm; P2m: 22-34 fT/cm vs. $17-18 \mathrm{fT} / \mathrm{cm})$, and therefore also the SNR has likely been higher. Probably, the shorter offset-to-onset interstimulus interval (ISI; $1 \mathrm{~s}$ vs. $4 \mathrm{~s}$ ) used in this study caused stronger adaptation or tuning of the auditory system to the temporal statistical structure of speech attenuating the responses. These issues are discussed more in the Neural correlates of speech complexity section. Another reason for differences may be that the stimulus sets were not the same and thus not acoustically identical. The frequency range of the distorted stimuli also 869 was different in these two studies because in this study the stimuli 870 were additionally downsampled before the USQ procedure, and there- 871 fore frequencies higher than $2.2 \mathrm{kHz}$ were filtered out to avoid aliasing. 872 Thus, the responses to the distorted stimuli may have been weaker be- 873 cause smaller number of neurons have been responding to the distorted 874 stimuli with narrower frequency band. Moreover, our previous and cur- 875 rent studies estimated the amplitudes and mean currents using differ- 876 ent gradiometers and ROIs which has likely affected on the results. $\quad 877$

The cortical activity during the sustained field elicited by words 878 showed sensitivity to speech degradation in that both the first and the 879 second presentations of the distorted stimuli resulted in stronger re- 880 sponses compared to the activity elicited by the intact stimuli. In the 881 gradiometer analysis, this effect was observed in the occipitotemporal, 882 parietal, and sensorimotor areas (on average, 28\% stronger mean ampli- 883 tudes for the distorted words), and in the ROI analysis, it was observed 884 in the SMG and STS (on average, 37\% stronger mean currents for the 885 distorted words). This increased activity for the distorted words is in ac- 886 cord with our previous study which found the same effect for sentence- 887 induced activity in the auditory cortex as well as in central inferior pari- 888 etal and posterior superior temporal areas (Tiitinen et al., 2012).

Neural correlates of speech complexity

The N1m amplitudes were on average 54\% stronger for vowels than 891 for words and sentences. This result was confirmed by ROI analyses in 892 the TTG and the posterior STG (studied within the same ROI), as well 893 as in the anterior SMG, the posterior STS and the posterior insula, 894 where words and sentences elicited, on average, 32\% weaker currents 895 than vowels. Also, the latency of the N1m seemed to reflect stimulus 896 complexity, with vowels resulting in the shortest latency and sentences 897 in the longest (with an average delay of $9 \mathrm{~ms}$ ). In contrast, while the 898 P2m amplitude was insensitive to speech complexity, the mean current 899 during the P2m time range was, on average, 25\% stronger for sentences 900 than for vowels in all of the four studied ROIs covering the TTG, the pos- 901 terior STG, the inferior SMG and the posterior STS. Also, vowels resulted 902 in a peak latency of the P2m which was some $35 \mathrm{~ms}$ earlier than that 903 associated with words and sentences. Further, the mean amplitude of 904 the sustained field was on average 15\% stronger when elicited by 905 words than when elicited by sentences in temporal, sensorimotor, 906 occipitotemporal, occipital, and parietal areas (i.e. in all the studied 907 areas but the frontal area)

The modulations of the N1m and P2m associated with stimulus com- 909 plexity tentatively suggest that continuous speech is processed different- 910 ly than isolated vowels in the auditory cortex during the first few 911 hundred milliseconds. Specifically, our results point to a possible context 912 effect, whereby the response to a vowel sound (be it isolated or the ini- 913 tial sound of a word or sentence) seems to be modulated by the com- 914 plexity and/or the sound duration of the preceding stimulus material. 915 A related finding has been made in a recent EEG study by Lanting et al. 916 (2013) who found the N1-P2 response to a probe tone to be reduced 917 as a function of the duration of the preceding adapter tone. However, it 918 is unclear to what extent this kind of adaptation due to stimulus repeti- 919 tion was occurring in the current experiment where the various stimuli 920 in the word and sentence sets, while certainly overlapping in spectral 921 content, were nonetheless not identical to one another. Moreover, in 922 the study by Lanting et al., the amplitude of the P2 response to pure 923 tones was shown to decrease with the duration of the adapter whereas 924 in our study, the mean currents during the P2m time range were, inter- 925 estingly, stronger for vowel presentation than for sentence presentation. 926 An alternative explanation could be that the modulations of the N1m 927 and $\mathrm{P} 2 \mathrm{~m}$ reflect inherent tuning of the auditory system to the temporal 928 statistical structure of speech. Indeed, there is evidence of a systematic 929 relationship between the phase of neural signals and the phase of the 930 temporal envelope of speech that might arise from a tendency of neural 931 systems to utilize rhythmic regularities of speech to form predictions 932 
about upcoming events (for reviews, see Golumbic et al., 2012; Peelle and Davis, 2012). The divergent characteristics of the $\mathrm{N} 1 \mathrm{~m}$ and the P2m responses associated with speech complexity may reflect their different neural origins and functional significances, a conclusion which is supported by recent EEG studies (Crowley and Colrain, 2004; Lanting et al., 2013; Ross and Tremblay, 2009; Tremblay et al., 2014). The differences between the transient responses elicited by vowels and to those elicited by words and sentences may also to some extent be related to the acoustic structure of the stimuli. The words in the word set were acoustically identical with the initial words of the sentences in the sentence set. In contrast, the acoustic structure of the isolated vowels slightly deviated from the acoustic structure of the initial vowels of the words and the sentences. First, the isolated vowels were $200 \mathrm{~ms}$ in duration whereas the duration of the initial vowels varied (i.e., due to the presence of both single and double vowels). Second, the onsets and offsets of the vowels were smoothed with a shorter (ramp length $5 \mathrm{~ms}$ ) Hann window than the words and sentences (ramp length $10 \mathrm{~ms}$ ). However, it is unlikely that this difference in the window length can alone explain the variations of brain activity as a function of stimulus complexity. For example, sentences that were acoustically identical with words also resulted in delayed $\mathrm{N} 1 \mathrm{~m}$ responses and diminished sustained fields compared to words.

\section{Conclusions}

The present findings suggest that the human ability to understand speech even under acoustically compromised conditions relies on memory-related top-down processes correlating the degraded auditory information with long-term memory traces for speech. Already a single exposure to intelligible, undistorted speech stimuli was shown to be sufficient to render their initially unintelligible, acoustically distorted counterparts intelligible, thus reflecting rapid neuroplasticity. Our results demonstrate that this increase in intelligibility depends on the complexity of the speech stimulus: the more complex the stimulus, the easier it is to recognize. This result is in line with the current models of speech perception suggesting that smaller linguistic units are encoded as part of a longer temporal unit, and intelligibility is achieved by integrating information over time. At the neural level, speech intelligibility was reflected by increased brain activity in the auditory cortex and surrounding areas for distorted speech stimuli after the exposure to their intact counterparts at latencies of $130-160$ ms. Thus, topdown information would seem to modify the processing of speech signals already at very early cortical stages of speech comprehension.

\section{Uncited reference}

Pantev et al., 1996

\section{Acknowledgments}

This research was supported by the Academy of Finland (grant No. 257811).

\section{Conflict of interest}

The authors declare no competing financial interests.

\section{References}

Ahissar, M., Hochstein, S., 2004. The reverse hierarchy theory of visual perceptual learning. Trends Cogn. Sci. 8, 457-464. http://dx.doi.org/10.1016/j.tics.2004.08.011.

Bodner, G.E., Masson, M.E.J., 2014. Memory recruitment: a backward idea about masked priming. Psychology of Learning and Motivation, 1st ed. Elsevier Inc. http://dx.doi. org/10.1016/B978-0-12-800283-4.00005-8.

Boothroyd, A., Nittrouer, S., 1988. Mathematical treatment of context effects in phoneme and word recognition. J. Acoust. Soc. Am. 84, 101-114. http://dx.doi.org/10.1121/1. 396976.
Bowers, J.S., 1996. Different perceptual codes support priming for words and 992 pseudowords: was Morton right all along? J. Exp. Psychol. Learn. Mem. Cogn. 22, 993 1336-1353. http://dx.doi.org/10.1037/0278-7393.22.6.1336.

Bradlow, A.R., Alexander, J.A., 2007. Semantic and phonetic enhancements for speech-in- 995 noise recognition by native and non-native listeners. J. Acoust. Soc. Am. 121, 2339-49. 996 http://dx.doi.org/10.1121/1.2642103.

Crowley, K.E., Colrain, I.M., 2004. A review of the evidence for P2 being an independent 998 component process: age, sleep and modality. Clin. Neurophysiol. 115, 732-744. 999 http://dx.doi.org/10.1016/j.clinph.2003.11.021. 1000

Dale, A.M., Liu, A.K., Fischl, B.R., Buckner, R.L., Belliveau, J.W., Lewine, J.D., Halgren, E., 2000. 1001 Dynamic statistical parametric mapping. Neuron 26, 55-67. http://dx.doi.org/10. 1002 1016/S0896-6273(00)81138-1.

Davis, M.H., Johnsrude, I.S., 2003. Hierarchical processing in spoken language comprehen- 1004 sion. J. Neurosci. 23, 3423-3431 (doi:10.1.1.58.2754). 1005

Davis, M.H., Johnsrude, I.S., 2007. Hearing speech sounds: top-down influences on the in- 1006 terface between audition and speech perception. Hear. Res. 229, 132-147. http://dx. 1007 doi.org/10.1016/j.heares.2007.01.014.

Desikan, R.S., Ségonne, F., Fischl, B., Quinn, B.T., Dickerson, B.C., Blacker, D., Buckner, R.L., 1009 Dale, A.M., Maguire, R.P., Hyman, B.T., Albert, M.S., Killiany, R.J., 2006. An automated 1010 labeling system for subdividing the human cerebral cortex on MRI scans into gyral 1011 based regions of interest. Neuroimage 31, 968-980. http://dx.doi.org/10.1016/j. 1012 neuroimage.2006.01.021.

Diamond, A., 1990. The development and neural bases of higher cognitive functions. In- 1014 troduction. Ann. N. Y. Acad. Sci. 608 (xiii-lvi). 1015

Diamond, R., Rozin, P., 1984. Activation of existing memories in anterograde amnesia. 1016 J. Abnorm. Psychol. 93, 98-105. http://dx.doi.org/10.1037/0021-843X.93.1.98. 1017

Dorfman, J., 1994. Sublexical components in implicit memory for novel words. J. Exp. 1018 Psychol. Learn. Mem. Cogn. 20, 1108-1125. http://dx.doi.org/10.1037/0278-7393. 1019 20.5 .1108 .

Eulitz, C., Diesch, E., Pantev, C., Hampson, S., Elbert, T., 1995. Magnetic and electric 1021 brain activity evoked by the processing of tone and vowel stimuli. J. Neurosci. 15, 1022 2748-55.

Forster, K., Booker, J., Schachter, Daniel, Davis, L., C., 1990. Masked repetition priming: lex- 1024 ical activation or novel memory trace? Bull. Psychon. Soc. 28, 341-345. http://dx.doi. 1025 org/10.3758/BF03334039.

Friederici, A.D. Kotz, S., Scott, S.K., Obleser, J, 2010. Disentangling syntax and intelligibility 1027 in auditory language comprehension. Hum. Brain Mapp. 31, 448-457. http://dx.doi. 1028 org/10.1002/hbm.20878.

Galambos, R., Makeig, S., Talmachoff, P.J., 1981. A 40-Hz auditory potential recorded from 1030 the human scalp. Proc. Natl. Acad. Sci. U. S. A. 78, 2643-2647. 1031

Giraud, A.L., Kell, C., Thierfelder, C., Sterzer, P., Russ, M.O., Preibisch, C., Kleinschmidt, A., 1032 2004. Contributions of sensory input, auditory search and verbal comprehension to 1033 cortical activity during speech processing. Cereb. Cortex 14, 247-255. http://dx.doi. 1034 org/10.1093/cercor/bhg124.

Golumbic, E.M.Z., Poppel, D., Schroeder, C.E., 2012. Temporal context in speech processing 1036 and attentional stream selection: a behavioral and neural perspective. Brain Lang. 1037 122, 151-161. http://dx.doi.org/10.1016/j.bandl.2011.12.010.

Gramfort, A., Luessi, M., Larson, E., Engemann, D.A., Strohmeier, D., Brodbeck, C., Goj, R., 1039 Jas, M., Brooks, T., Parkkonen, L., Hämäläinen, M., 2013. MEG and EEG data analysis 1040 with MNE-Python. Front. Neurosci. 7, 267. http://dx.doi.org/10.3389/fnins.2013. 1041 00267.

Gramfort, A., Luessi, M., Larson, E., Engemann, D.A., Strohmeier, D., Brodbeck, C., 1043 Parkkonen, L., Hämäläinen, M.S., 2014. MNE software for processing MEG and EEG 1044 data. Neuroimage 86, 446-460. http://dx.doi.org/10.1016/j.neuroimage.2013.10.027. 1045

Gray, R.M., 1990. Quantization noise spectra. IEEE Trans. Inf. Theory 36, 1220-1244. 1046 http://dx.doi.org/10.1109/18.59924. 1047

Gutschalk, A., Patterson, R.D., Rupp, A., Uppenkamp, S., Scherg, M., 2002. Sustained mag- 1048 netic fields reveal separate sites for sound level and temporal regularity in human au- 1049 ditory cortex. Neuroimage 15, 207-216. http://dx.doi.org/10.1006/nimg.2001.0949. 1050

Hämäläinen, M.S., Ilmoniemi, R.J., 1994. Interpreting magnetic fields of the brain: mini- 1051 mum norm estimates. Med. Biol. Eng. Comput. 32, 35-42. http://dx.doi.org/10. 1052 1007/BF02512476.

Hannemann, R., Obleser, J., Eulitz, C., 2007. Top-down knowledge supports the retrieval of 1054 lexical information from degraded speech. Brain Res. 1153, 134-143. http://dx.doi. 1055 org/10.1016/j.brainres.2007.03.069. 1056

Hari, R., Hämäläinen, M., Joutsiniemi, S.L., 1989. Neuromagnetic steady-state responses to 1057 auditory stimuli. J. Acoust. Soc. Am. 86, 1033-1039. http://dx.doi.org/10.1121/1. 1058 398093.

Hervais-Adelman, A.G., Carlyon, R.P., Johnsrude, I.S., Davis, M.H., 2012. Brain regions re- 1060 cruited for the effortful comprehension of noise-vocoded words. Lang. Cogn. Process. 1061 27, 1145-1166. http://dx.doi.org/10.1080/01690965.2012.662280. 1062

Huotilainen, M., Tiitinen, H., Lavikainen, J., Ilmoniemi, R.J., Pekkonen, E., Sinkkonen, J., 1063 Laine, P., Näätänen, R., 1995. Sustained fields of tones and glides reflect tonotopy of 1064 the auditory cortex. Neuroreport 6, 841-844. http://dx.doi.org/10.1097/00001756- 1065 199504190-00004.

Hyvärinen, A., Oja, E., 2000. Independent component analysis: algorithms and applica- 1067 tions. Neural Netw. 13, 411-430. http://dx.doi.org/10.1016/S0893-6080(00)00026-5. 1068

Jääskeläinen, I.P., Ahveninen, J., Belliveau, J.W., Raij, T., Sams, M., 2007. Short-term plastic- 1069 ity in auditory cognition. Trends Neurosci. 30, 653-661. http://dx.doi.org/10.1016/j. 1070 tins.2007.09.003.

Kalikow, D.N., Stevens, K.N., Elliott, L.L., 1977. Development of a test of speech intelligibil- 1072 ity in noise using sentence materials with controlled word predictability. J. Acoust. 1073 Soc. Am. 61, 1337-1351. http://dx.doi.org/10.1121/1.381436. 1074

Keceli, S., Inui, K., Okamoto, H., Otsuru, N., Kakigi, R., 2012. Auditory sustained field re- 1075 sponses to periodic noise. BMC Neurosci. 13, 7. http://dx.doi.org/10.1186/1471- 1076 2202-13-7. 
Kirmse, U., Jacobsen, T., Schröger, E., 2009. Familiarity affects environmental sound processing outside the focus of attention: an event-related potential study. Clin. Neurophysiol. 120, 887-896. http://dx.doi.org/10.1016/j.clinph.2009.02.159.

Lanting, C.P., Briley, P.M., Sumner, C.J., Krumbholz, K., 2013. Mechanisms of adaptation in human auditory cortex. J. Neurophysiol. 110, 973-983. http://dx.doi.org/10.1152/jn. 00547.2012.

Leff, A.P., Schofield, T.M., Stephan, K.E., Crinion, J.T., Friston, K.J., Price, C.J., 2008. The cortical dynamics of intelligible speech. J. Neurosci. 28, 13209-13215. http://dx.doi. org/10.1523/JNEUROSCI.2903-08.2008.

Liikkanen, L., Tiitinen, H., Alku, P., Leino, S., Yrttiaho, S., May, P.J.C., 2007. The righthemispheric auditory cortex in humans is sensitive to degraded speech sounds. Neuroreport 18, 601-605. http://dx.doi.org/10.1097/WNR.0b013e3280b07bde.

Lin, F.-H., Belliveau, J.W., Dale, A.M., Hämäläinen, M.S., 2006a. Distributed current estimates using cortical orientation constraints. Hum. Brain Mapp. 27, 1-13. http://dx. doi.org/10.1002/hbm.20155.

in, F.-H., Witzel, T., Ahlfors, S.P., Stufflebeam, S.M., Belliveau, J.W., Hämäläinen, M.S., 2006b. Assessing and improving the spatial accuracy in MEG source localization by depth-weighted minimum-norm estimates. Neuroimage 31, 160-171. http://dx.doi. org/10.1016/j.neuroimage.2005.11.054.

Lotto, A.J., Hickok, G.S., Holt, L.L., 2009. Reflections on mirror neurons and speech perception. Trends Cogn. Sci. 13, 110-114. http://dx.doi.org/10.1016/j.tics.2008.11.008.

Mäkelä, A.M., Alku, P., Mäkinen, V., Valtonen, J., May, P., Tiitinen, H., 2002. Human cortical dynamics determined by speech fundamental frequency. Neuroimage 17 1300-1305. http://dx.doi.org/10.1006/nimg.2002.1279.

Mäkelä, A.M., Alku, P., Mäkinen, V., Tiitinen, H., 2004. Glides in speech fundamental frequency are reflected in the auditory $\mathrm{N} 1 \mathrm{~m}$ response. Neuroreport 15, 1205-1208. http://dx.doi.org/10.1097/01.wnr.0000126212.56622.38.

Mäkinen, V., 2006. Analysis of the Structure of Time-frequency Information in Electromagnetic Brain Signals. Helsinki University of Technology.

Marinkovic, K., Cox, B., Reid, K., Halgren, E., 2004. Head position in the MEG helmet affects the sensitivity to anterior sources. Neurol. Clin. Neurophysiol. 30, 1-4. http://dx.doi. org/10.1016/j.biotechadv.2011.08.021.Secreted.

Marslen-Wilson, W.D., 1987. Functional parallelism in spoken word-recognition. Cognition 25, 71-102. http://dx.doi.org/10.1016/0010-0277(87)90005-9.

May, P.J.C., Tiitinen, H., 2010. Mismatch negativity (MMN), the deviance-elicited auditory deflection, explained. Psychophysiology 47, 66-122. http://dx.doi.org/10.1111/j. 1469-8986.2009.00856x.

McClelland, J.L., Elman, J.L., 1986. The TRACE model of speech perception. Cogn. Psychol. 18, 1-86. http://dx.doi.org/10.1016/0010-0285(86)90015-0.

McClelland, J.L., Mirman, D., Holt, L.L., 2006. Are there interactive processes in speech perception? Trends Cogn. Sci. 10, 363-369. http://dx.doi.org/10.1016/j.tics.2006.06.007. Miettinen, I., Tiitinen, H., Alku, P., May, P.J.C., 2010. Sensitivity of the human auditory cortex to acoustic degradation of speech and non-speech sounds. BMC Neurosci. 11, 24 http://dx.doi.org/10.1186/1471-2202-11-24.

Miettinen, I., Alku, P., Salminen, N., May, P.J.C., Tiitinen, H., 2011. Responsiveness of the human auditory cortex to degraded speech sounds: reduction of amplitude resolution vs, additive noise. Brain Res. 1367, 298-309. http://dx.doi.org/10.1016/j. brainres.2010.10.037.

Miettinen, I., Alku, P., Yrttiaho, S., May, P.J.C., Tiitinen, H., 2012. Cortical processing of degraded speech sounds: effects of distortion type and continuity. Neuroimage 60 1036-1045. http://dx.doi.org/10.1016/j.neuroimage.2012.01.085.

Miller, G.A., Isard, S., 1963. Some perceptual consequences of linguistic rules. J. Verbal Learn. Verbal Behav. 2, 217-228. http://dx.doi.org/10.1016/S0022-5371(63)80087-0.

Morton, J., 1979. Facilitation in word recognition: experiments causing change in the logogen model. Process. Visible Lang. 13, 259-268. http://dx.doi.org/10.1007/978-14684-0994-9.

Möttönen, R., Calvert, G.A., Jääskeläinen, I.P., Matthews, P.M., Thesen, T., Tuomainen, J, Sams, M., 2006. Perceiving identical sounds as speech or non-speech modulates activity in the left posterior superior temporal sulcus. Neuroimage 30, 563-569. http://dx.doi.org/10.1016/j.neuroimage.2005.10.002.

Näätänen, R., Picton, T., 1987. The N1 wave of the human electric and magnetic response to sound: a review and an analysis of the component structure. Psychophysiology 24 , 375-425. http://dx.doi.org/10.1111/j.1469-8986.1987.tb00311.x.

Obleser, J., Lahiri, A., Eulitz, C., 2004. Magnetic brain response mirrors extraction of phonological features from spoken vowels. J. Cogn. Neurosci. 16, 31-39. http://dx.doi. org/10.1162/089892904322755539.

Obleser, J., Wise, R.J.S., Alex Dresner, M., Scott, S.K., 2007. Functional integration across brain regions improves speech perception under adverse listening conditions. J. Neurosci. 27, 2283-2289. http://dx.doi.org/10.1523/JNEUROSCI.4663-06.2007.
Obleser, J., Eisner, F., Kotz, S.A., 2008. Bilateral speech comprehension reflects differential 1147 sensitivity to spectral and temporal features. J. Neurosci. 28, 8116-8123. http://dx. 1148 doi.org/10.1523/JNEUROSCI.1290-08.2008.

Okada, K., Rong, F., Venezia, J., Matchin, W., Hsieh, I.H., Saberi, K., Serences, J.T., Hickok, G., 1150 2010. Hierarchical organization of human auditory cortex: evidence from acoustic 1151 invariance in the response to intelligible speech. Cereb. Cortex 20, 2486-2495. 1152 http://dx.doi.org/10.1093/cercor/bhp318.

Okamoto, H. Stracke, H. Bermudez P. Pantev, C, 2011. Sound processing hierarchy with- 1154 in human auditory cortex. J. Cogn. Neurosci. 23, 1855-1863. http://dx.doi.org/10. 1155 1162/jocn.2010.21521.

Pantev, C., Roberts, L.E., Elbert, T., Roß, B., Wienbruch, C., 1996. Tonotopic organization 1157 of the sources of human auditory steady-state responses. Hear. Res. 101, 62-74. 1158 http://dx.doi.org/10.1016/S0378-5955(96)00133-5.

Pantev, C., Roberts, L.E., Schulz, M., Engelien, A., Ross, B., 2001. Timbre-specific enhance- 1160 ment of auditory cortical representations in musicians. Neuroreport 12, 169-174. 1161 http://dx.doi.org/10.1097/00001756-200101220-00041. 1162

Peelle, J.E., Davis, M.H., 2012. Neural oscillations carry speech rhythm through to compre- 1163 hension. Front. Psychol. 3, 1-17. http://dx.doi.org/10.3389/fpsyg.2012.00320. 1164

Peelle, J.E., Johnsrude, I.S., Davis, M.H., 2010. Hierarchical processing for speech in human 1165 auditory cortex and beyond. Cereb. Cortex 4, 1-3. http://dx.doi.org/10.1093/cercor/ 1166 bhp318.

1167

Ross, B., Tremblay, K., 2009. Stimulus experience modifies auditory neuromagnetic re- 1168 sponses in young and older listeners. Hear. Res. 248, 48-59. http://dx.doi.org/10. 1169 1016/j.heares.2008.11.012 1170

Salmelin, R, 2007. Clinical neurophysiology of language: the MEG approach. Clin. 1171 Neurophysiol. 118, 237-254. http://dx.doi.org/10.1016/j.clinph.2006.07.316. 1172

Scott, S.K., Mcgettigan, C., Eisner, F., 2009. A little more conversation, a little less action - 1173 candidate roles for motor cortex in speech perception. Nat. Rev. Neurosci. 10, 1174 295-302. http://dx.doi.org/10.1038/nrn2603.A.

1175

Shahin, A.J., Bishop, C.W., Miller, L.M., 2009. Neural mechanisms for illusory filling-in 1176 of degraded speech. Neuroimage 44, 1133-1143. http://dx.doi.org/10.1016/j. 1177 neuroimage.2008.09.045

1178

Smiljanic, R., Sladen, D. 2013. Acoustic and semantic enhancements for children with co- 1179 chlear implants. J. Speech Lang. Hear. Res. 56, 1085-96. http://dx.doi.org/10.1044/ 1180 1092-4388(2012/12-0097).

Tallon-Baudry, C. Bertrand, O., Delpuech, C., Pernier, J., 1997. Oscillatory gamma-band 1182 $(30-70 \mathrm{~Hz})$ activity induced by a visual search task in humans. J. Neurosci. 17, 1183 722-734.

Taulu, S., Simola, J., 2006. Spatiotemporal signal space separation method for rejecting 1185 nearby interference in MEG measurements. Phys. Med. Biol. 51, 1759-1768. http:// 1186 dx.doi.org/10.1088/0031-9155/51/7/008.

1187

Tiitinen, H., Mäkelä, A.M., Mäkinen, V., May, P.J.C., Alku, P., 2005. Disentangling the effects 1188 of phonation and articulation: hemispheric asymmetries in the auditory N1m re- 1189 sponse of the human brain. BMC Neurosci. 6, 62. http://dx.doi.org/10.1186/1471- 1190 2202-6-62.

Tiitinen, H., Miettinen, I., Alku, P., May, P.J.C., 2012. Transient and sustained cortical activ- 1192 ity elicited by connected speech of varying intelligibility. BMC Neurosci. 13, 157. 1193 http://dx.doi.org/10.1186/1471-2202-13-157.

Tremblay, K.L., Ross, B., Inoue, K., McClannahan, K., Collet, G., 2014. Is the auditory evoked 1195 P2 response a biomarker of learning? Front. Syst. Neurosci. 8, 28. http://dx.doi.org/10. 1196 3389/fnsys.2014.00028.

Tulving, E., Schacter, D.L., 1990. Priming and human memory systems. Science 247, 1198 301-306. http://dx.doi.org/10.1126/science.2296719. 1199

Tulving. E., Schacter, D., Stark, H., 1982. Priming effects in word-fragment completion are 1200 independent of recognition memory. J. Exp. Psychol. Learn. Mem. Cogn. http://dx.doi. 1201 org/10.1037/0278-7393.8.4.336.

Valentini-Botinhao, C. Wester, M., 2014. Using linguistic predictability and the Lombard Q9 effect to increase the intelligibility of synthetic speech in noise. INTERSPEECH 2014, 1204 pp. 2063-2067 (Signapore)

Wild, C.J., Yusuf, A., Wilson, D.E., Peelle, J.E., Davis, M.H., Johnsrude, I.S., 2012. Effortful lis- 1206 tening: the processing of degraded speech depends critically on attention. J. Neurosci. 1207 32, 14010-14021. http://dx.doi.org/10.1523/JNEUROSCI.1528-12.2012. 1208

Ylinen, S., Huotilainen, M., 2007. Is there a direct neural correlate for memory-trace for- 1209 mation in audition? Neuroreport 18, 1281-1284. http://dx.doi.org/10.1097/WNR. 1210 0b013e32826fb38a.

Yrttiaho, S., Alku, P., May, P.J.C., Tiitinen, H., 2009. Representation of the vocal roughness 1212 of aperiodic speech sounds in the auditory cortex. J. Acoust. Soc. Am. 125, 1213 3177-3185. http://dx.doi.org/10.1121/1.3097471. 